OPEN ACCESS

Edited by:

Johannes Boltze,

University of Warwick,

United Kingdom

Reviewed by:

Livio Luongo,

Second University of Naples, Italy

Meliha Karsak,

University Medical Center

Hamburg-Eppendorf, Germany

Natsuo Ueda,

Kagawa University, Japan

*Correspondence:

Faramarz Dehghani

Faramarz.Dehghani@

medizin.uni-halle.de

${ }^{\dagger}$ These authors have contributed equally to this work

Specialty section:

This article was submitted to

Neurodegeneration,

a section of the journal

Frontiers in Neuroscience

Received: 15 May 2019 Accepted: 18 October 2019 Published: 07 November 2019

Citation:

Hohmann U, Pelzer M, Kleine J,

Hohmann T, Ghadban C and Dehghani F (2019) Opposite Effects of

Neuroprotective Cannabinoids,

Palmitoylethanolamide, and

2-Arachidonoylglycerol on Function

and Morphology of Microglia.

Front. Neurosci. 13:1180.

doi: 10.3389/fnins.2019.01180

\section{Opposite Effects of Neuroprotective Cannabinoids, Palmitoylethanolamide, and 2-Arachidonoylglycerol on Function and Morphology of Microglia}

\author{
Urszula Hohmannt, Markus Pelzert, Joshua Kleine, Tim Hohmann, Chalid Ghadban and \\ Faramarz Dehghani*
}

Department of Anatomy and Cell Biology, Medical Faculty, Martin Luther University Halle-Wittenberg, Halle (Saale), Germany

Various studies performed in cultured cells and in in vivo models of neuronal damage showed that cannabinoids exert a neuroprotective effect. The increase in cannabinoids and cannabinoid like substances after stroke has been postulated to limit the content of neuronal injury. As well-accepted, inflammation, and neuronal damage are coupled processes and microglial cells as the main intrinsic immunological effector within the brain play a central role in their regulation. Treatment with the endocannabinoid, 2-arachidonoylglycerol (2-AG) or the endocannabinoid-like substance, palmitoylethanolamide (PEA) affected microglial cells and led to a decrease in the number of damaged neurons after excitotoxical lesion in organotypic hippocampal slice cultures (OHSC). 2-AG activated abnormal cannabidiol (abn-CBD) receptor, PEA was shown to mediate neuroprotection via peroxisome proliferator-activated receptor (PPAR) $\alpha$. Despite the known neuroprotective and anti-inflammatory properties, the potential synergistic effect, namely possible entourage effect after treatment with the combination of these two protective cannabinoids has not been examined yet. After excitotoxical lesion OHSC were treated with PEA, 2-AG or a combination of both and the number of damaged neurons was evaluated. To investigate the role of microglial cells in PEA and 2-AG mediated protection, primary microglial cell cultures were treated with lipopolysaccharide (LPS) and 2-AG, PEA or a combination of those. Thereafter, we measured NO production, ramification index, proliferation and PPAR $\alpha$ distribution in microglial cells. While PEA or 2-AG alone were neuroprotective, their coapplication vanished the protective effect. This behavior was independent of microglial cells. Furthermore, PEA and 2-AG had contrary effects on ramification index and on NO production. No significant changes were observed in the proliferation rate of microglial cells after treatment. The expression of PPAR $\alpha$ was not changed upon stimulation with PEA or 2-AG, but the distribution was significantly altered. 2-AG and 
PEA mediated neuroprotection was abolished when co-applied. Both cannabinoids exert contrary effects on morphology and function of microglial cells. Co-application of both cannabinoids with different targets did not lead to a positive additive effect as expected, presumably due to the contrary polarization of microglial cells.

\section{Keywords: 2-arachidonoylglycerol, neuroprotection, microglial cells}

\section{INTRODUCTION}

Traumatic brain injury affects a high number of young adults and their hospitalization is still a significant public challenge (Meaney et al., 2014). During neuronal damage a complex series of mechanisms becomes activated (Dirnagl et al., 2003; Kunz et al., 2010). Energy failure leads to calcium overload, depolarization of neurons and release of neurotransmitters with consecutive excitotoxicity, induced through overstimulation from excitatory receptors like NMDA receptor. This cascade is followed by activation of proteolytic enzymes and release of reactive oxygen species, damaging mitochondria, followed by apoptosis and neuronal death (Bruce et al., 1995; Kunz et al., 2010). Injured neuronal tissue releases pro-inflammatory cytokines leading to migration of inflammatory cells to the damaged site and inflammation (Jassam et al., 2017). Microglial cells play a crucial role during this process of secondary neuronal damage since they are the immunocompetent cells of the central nervous system (Kettenmann et al., 2011).

Cannabinoids positively affect cellular and molecular processes during ischemic, excitotoxical, or traumatic brain injury and were shown to be protective in different models mostly via microglial cells. All kind, plant-derived (isolated from Cannabis sativa), endo- (animal-derived) and synthetic cannabinoids were shown to affect neuronal damage (Kreutz et al., 2007, 2009; Mechoulam and Shohami, 2007; Koch et al., 2011a,b; Grabiec et al., 2012; Fernández-Ruiz et al., 2015; Guida et al., 2017; Belardo et al., 2019; Impellizzeri et al., 2019). Using the model of excitotoxically lesioned OHSC the number of damaged neurons was significantly reduced after treatment with endocannabinoids, like $N$-arachidonoyl dopamine, 2-arachidonoylglycerol (2-AG) or PEA associated with altered microglial cell number but not the phytocannabinoid, $\Delta-9$ tetrahydrocannabinol (Kreutz et al., 2007; Koch et al., 2011a; Grabiec et al., 2012).

2-AG was shown to induce protection after neuronal lesion and to reduce the amount of tumor necrosis factor $\alpha$ released from LPS activated microglial cells (Facchinetti et al., 2003). Both, PEA and 2-AG are produced in the central nervous system and upregulated after neuronal damage (Kondo et al., 1998; Panikashvili et al., 2001; Franklin et al., 2003) and were shown to exhibit neuroprotection in several in vivo and in vitro models (Koch et al., 2011a; Beggiato et al., 2018; Herrera et al., 2018). Anti-inflammatory effects of PEA were associated with PPAR $\alpha$

Abbreviations: 2-AG, 2-arachidonoylglycerol; abn-CBD, abnormal cannabidiol; abn-CBDR, abn-CBD-sensitive receptor; $\mathrm{CB}$, cannabinoid receptor; $\mathrm{CBD}$, cannabidiol; div, day in vitro; iNOS, inducible nitric oxide synthase; LPS, lipopolysaccharide; NMDA, N-methyl-D -aspartate, NO, nitric oxide; OHSC, organotypic hippocampal slice cultures; PEA, palmitoylethanolamide; PPAR, peroxisome proliferator-activated receptor. palmitoylethanolamide, peroxisome proliferator-activated receptor, activation (LoVerme et al., 2005; Koch et al., 2011a; Citraro et al., 2013), and induction of PPAR $\alpha$ expression was related in parallel to protective effects (Genovese et al., 2008; Koch et al., 2011a). A recent study demonstrated the presence of PPAR $\alpha$ in different brain regions on neurons, astrocytes and microglial cells (Warden et al., 2016). Effects of 2-AG were abolished by O1918 and cannabidiol (CBD), both antagonists of the abn-CBD sensitive receptor (abn-CBDR) (Kreutz et al., 2009). Evidence for functional abn-CBDR in the brain was pharmacologically found on microglial cells (Franklin and Stella, 2003; Walter et al., 2003; Kreutz et al., 2009). Consequently, 2-AG mediated protection depends on the presence of microglial cells as confirmed by microglial cells depletion (Kohl et al., 2003; Kreutz et al., 2009).

2-AG mediated protective properties were demonstrated in a variety of animal models of degenerative neurological disorders including multiple sclerosis, Parkinson's disease, and Alzheimer's disease (Scotter et al., 2010; Pertwee, 2014; Mounsey et al., 2015) and in vitro in astrocytes exposed to oxygenglucose deprivation (Wang et al., 2015, 2018). 2-AG is the most abundant endocannabinoid in the brain and known to bind and activate $\mathrm{CB}_{1}$ and $\mathrm{CB}_{2}$ receptors. The treatment with exogenous 2 - $A G$ attenuated neuronal damage in vivo partly via $\mathrm{CB}_{1}$ and mimicked the effects reported after aplication of synthetic $\mathrm{CB}_{2}$ agonists. Some effects were absent in $\mathrm{CB}_{1}{ }^{-/-}$mice (Mechoulam and Shohami, 2007; Magid et al., 2019). Furthermore, Carrier et al. (2004) observed that 2-AG affected microglial cells via $\mathrm{CB}_{2}$. However, in rat OHSC and after NMDA damage effects of 2-AG were not blocked by $\mathrm{CB}_{1}$ or $\mathrm{CB}_{2}$ antagonists but inhibited by abnormal cannabidiol sensitive receptor (abn$\mathrm{CBDR}$ ) antagonists. These results make an involvement of $\mathrm{CB}_{1}$ or $\mathrm{CB}_{2}$ in 2-AG mediated neuroprotection unlikely (Kreutz et al., 2009). Application of PEA improved neuronal survival in vitro in primary mouse cortical astrocyte-neuron co-cultures (Beggiato et al., 2018) and in cortical neurons after hypoxia (Portavella et al., 2018). PEA possessed further beneficial properties in animal models of degenerative neurological disorders including vascular dementia (Siracusa et al., 2017). PEA and anandamide, if administrated together reduced the pain response 100-fold more potently than both substances alone and induced stronger vascular effects (Calignano et al., 1998; Ho et al., 2008). Such a co-application of two active cannabinoids increased their efficacy via the so called entourage effect, which is an endogenous cannabinoid molecular regulation route (Ben-Shabat et al., 1998). Ben-Shabat et al. (1998) demonstrated for the first time, that two inactive compounds, namely 2-linoleoylglycerol and 2palmitoylglycerol potentiate the binding of $2-\mathrm{AG}$ to the $\mathrm{CB}_{1}$ and thereby its effects. Additionally, 2-linoleoylglycerol significantly inhibited the inactivation of 2-AG. Similarly, PEA was reported to prevent the inactivation of anandamide (Jonsson et al., 2001; 
Ho et al., 2008) indicating possible entourage effect. Microglial cells, the main immune cell of the central nervous system, has a ramified morphology and is stationary, surveying its surrounding if in an undamaged and non-inflammatory state (Smith et al., 2012). In pathologies, like neuropathic pain $\mathrm{CB}_{2}$ expression increased in parallel to appearance of activated microglial cells. $\mathrm{CB}_{2}$ ligands significantly alleviated the pain indicating that microglial cells are a main target of cannabinoids (Zhang et al., 2003; Luongo et al., 2010). During neuronal damage microglial cells become amoeboid, migrate to the lesion site, proliferate and can be affected by cannabinoids, as for example PEA potentiates microglial cell motility (Franklin et al., 2003; Vinet et al., 2012). Microglial cells mediate neuroprotection, but can also contribute to the damage, e.g., by upregulation of iNOS, an enzyme producing toxic amounts of NO from L-arginine (Garry et al., 2015). 2-AG was shown to induce the iNOS expression and NO production (Lipina and Hundal, 2017) and to stimulate $\mathrm{NO}$ release in invertebrate immune cells via $\mathrm{CB}_{1}$ (Stefano et al., 2000). Contrary, NO donors were found to be neuroprotective (Kakizawa et al., 2007). Little is known about the influence of endocannabinoids on arginase, which inhibits the production of $\mathrm{NO}$ as a competing regulatory enzyme in the arginase-NOsynthase regulatory system in microglial cells. In peripheral immune cells $\Delta$-9-tetrahydrocannabinol and AM1241, an $\mathrm{CB}_{2}$ agonist induced arginase 1 expression (Hegde et al., 2010; Ma et al., 2015).

Earlier studies consistently reported about increased levels of endocannabinoids, such as PEA or 2-AG after neuronal injury. A question is raised why the secondary neuronal damage can't be prevented despite the high presence of neuroprotective substances. Since both endocannabinoids $2-A G$ and PEA if applied exogenously were shown to be neuroprotective via abn-CBDR or PPAR $\alpha$ respectively, we asked whether the neuroprotective potential of both is additive. To assess a potential entourage effect between 2-AG and PEA on neuroprotective properties OHSC were excitotoxically lesioned and treated with PEA, 2-AG or combination of both. As mentioned, PEA and 2AG target microglial cells. Therefore, their effects on function and morphology of primary microglial cells were investigated in untreated or LPS stimulated cultures. Ramification index, NO production, proliferation index, and temporal PPAR $\alpha$ distribution were determined overtime.

\section{MATERIALS AND METHODS}

All experiments involving animal material were performed in accordance with the directive 2010/63/EU of the European Parliament and the Council of the European Union (22.09.2010) and approved by local authorities of the State of SaxonyAnhalt (permission number: I11M18, date: 01.12.2012) protecting animals and regulating tissue collection used for scientific purposes.

\section{Materials}

2-Arachidonylglycerol (2-AG, $10 \mathrm{nM}$, stock solved in DMSO; Tocris, Minneapolis, MN, United States, cat No. 1298),
Clodronate $(100 \mu \mathrm{g} / \mathrm{ml}$, stock solved in Aqua; Bayer Vital GmbH GB; PZN: 04299668), Palmitoylethanolamide (PEA, $10 \mathrm{nM}$, stock solved in DMSO, Tocris, cat No. 0879), LPS (10 ng/ml, stock solved in Aqua; Sigma-Aldrich, cat No. L8274) and NMDA (50 $\mu \mathrm{M}$, stock solved in Aqua bidest., Sigma-Aldrich, cat No. M3262) were used and applied to the culture medium according to treatment protocol.

\section{Cell Culture}

Primary microglia astrocyte co-cultures were prepared from 1 day old Wistar rats and cultured, as described earlier (Kohl et al., 2003; Grabiec et al., 2012). Briefly brains were treated with $0.5 \mathrm{mg} / \mathrm{mL}$ DNAse (Worthington, Bedford, MA, United States) and $4 \mathrm{mg} / \mathrm{mL}$ trypsin (Merck Millipore, Billerica, MA, United States) solved in Hank's balanced salts solution (Invitrogen, Carlsbad, CA, United States). Cells were cultured in DMEM (Invitrogen, cat No. 41965-062) with 10\% FBS (Invitrogen, cat No. 10500-062) and $1 \mathrm{ml}$ streptomycin/penicillin (Invitrogen). After 10 days microglial cells were isolated from astrocytic monolayer and seeded into well plates.

For immunocytochemical analysis 50,000 cells were placed on glass cover slips coated with poly-L-lysin and allowed to attach for $3 \mathrm{~h}$. Cannabinoids were applied for $48 \mathrm{~h}$ to determine the microglial cells morphology. Bromodeoxyuridine (BrdU) (0.01 mM, Sigma-Aldrich) was added to the culture medium $16 \mathrm{~h}$ before the fixation to assess proliferation. Intracellular distribution of PPAR $\alpha$ was analyzed 1, 6, and $24 \mathrm{~h}$ after treatment. The cells were fixed with $4 \%$ paraformaldehyde (Sigma-Aldrich, Munich, Germany) for $10 \mathrm{~min}$ and stored in $0.02 \mathrm{M}$ PBS at $4^{\circ} \mathrm{C}$ for further analysis.

For NO measurement supernatant of 50,000 cells treated for $72 \mathrm{~h}$ with cannabinoids was collected and stored at $-80^{\circ} \mathrm{C}$ until further analysis.

\section{Organotypic Hippocampal Slice Cultures (OHSC)}

Organotypic hippocampal slice cultures were prepared from 7 to 9 day old Wistar rats as reported earlier (Grabiec et al., 2012, 2017; Hagemann et al., 2013; Hohmann et al., 2017, 2019) and kept at $35^{\circ} \mathrm{C}$ in a fully humidified atmosphere with $5 \%(\mathrm{v} / \mathrm{v})$ $\mathrm{CO}_{2}$. Culture medium was changed every other day. After 6 days in vitro experiments were started. All slices despite the control groups were treated with NMDA $(50 \mu \mathrm{M})$ for $4 \mathrm{~h}$. OHSC were treated with PEA $(10 \mathrm{nM})$ or $2-\mathrm{AG}(10 \mathrm{nM})$ or their combination for $72 \mathrm{~h}$. The NMDA treated set of excitotoxically damaged OHSC was supplemented with 2-AG, PEA or combination of both or left untreated to asses an effect on neuronal damage in region of dentate gyrus.

To investigate the role of microglial cells OHSC were incubated with $100 \mu \mathrm{g} / \mathrm{ml}$ clodronate from 1 to 6 day in vitro (div). Clodronic acid, a bisphosphonate, affects only cells of the monocytic lineage and leads to apoptosis of microglia and macrophages (Kohl et al., 2003) (Figures 1, 2A).

All slice cultures were treated with propidium iodide (PI; Merck Millipore, cat No. 537059) $2 \mathrm{~h}$ prior to fixation to visualize 

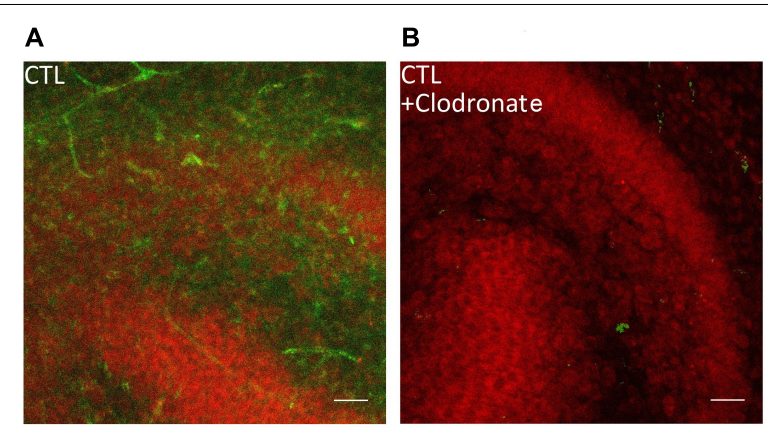

C

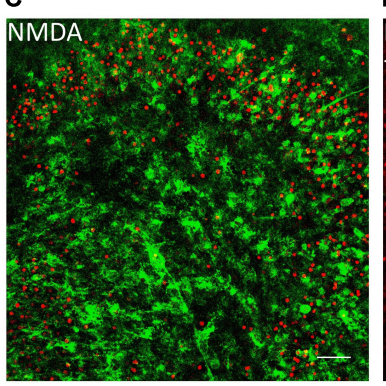

D

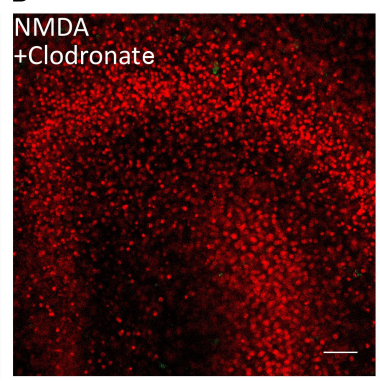

FIGURE 1 | Clodronate depletes microglial cells from OHSC. (A) PI labeled control OHSC with dentate gyrus and CA3. No PI positive nuclei (red) and ramified $\mathrm{IB}_{4}$ (green) labeled microglial cells are visible. (B) Application of clodronate to $\mathrm{CTL}$ slices removed $\mathrm{IB}_{4}$ positive microglial cells without damaging the neurons. (C) Treatment with NMDA led to massive increase in PI positive cells and $\mathrm{IB}_{4}$ positive microglia. (D) Depletion of microglial cells led to exacerbation of neuronal damage after NMDA treatment in OHSC. Scale bar $=50 \mu \mathrm{m}$.

degenerated neurons (Ebrahimi et al., 2010; Grabiec et al., 2012, 2017; Hezel et al., 2012).

\section{Immuno-, Lectinhistochemistry and Staining}

All antibodies and lectins and conditions used are listed in Table 1. For labeling of incorporated BrdU fixed microglial cells were incubated with $2 \mathrm{~mol} / \mathrm{l} \mathrm{HCl}$ for $1 \mathrm{~h}$, washed three times with PBS/Triton and pre-incubated with normal horse serum (Gibco BRL, Life Technologies, Eggenstein, Germany, cat No. 31874, dilution 1:20) in PBS/Triton. Afterward anti-BrdU antibody (Table 1) was applied for $1 \mathrm{~h}$, followed by incubation with Alexa 488 conjugated goat anti-mouse antibody for $1 \mathrm{~h}$. Cells were washed three times with PBS/Triton and incubated with 4',6-diamidino-2-phenylindole (DAPI, Sigma-Aldrich, Munich, Germany, cat No. D9542).

Organotypic hippocampal slice cultures were stained with Alexa 488 conjugated $\mathrm{IB}_{4}$ (Molecular Probes). All fluorescence stained slides were washed with PBS/Triton and Aqua dest. before covering with mounting medium (DAKO, Agilent Technologies, Inc., Santa Clara, CA, United States).

For measurement of ramification index biotin labeled $\mathrm{IB}_{4}$ was used. To measure the PPAR $\alpha$ distribution, an anti-PPAR $\alpha$ antibody was applied as characterized before (Koch et al., 2011a). After washing with PBS, biotinylated goat anti-rabbit antibody
A

\section{Treatment protocol}
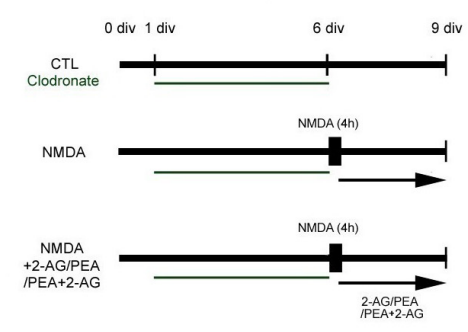

B
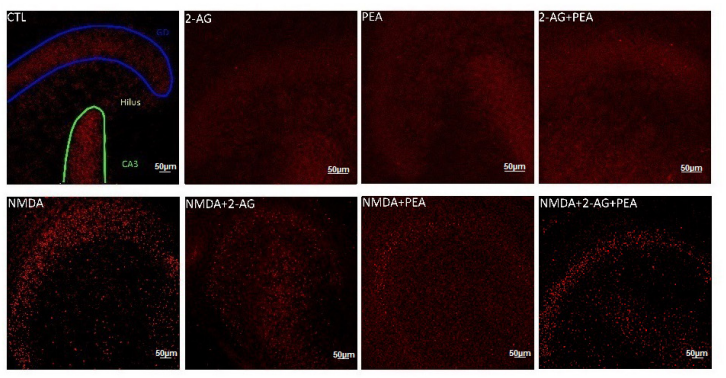

C

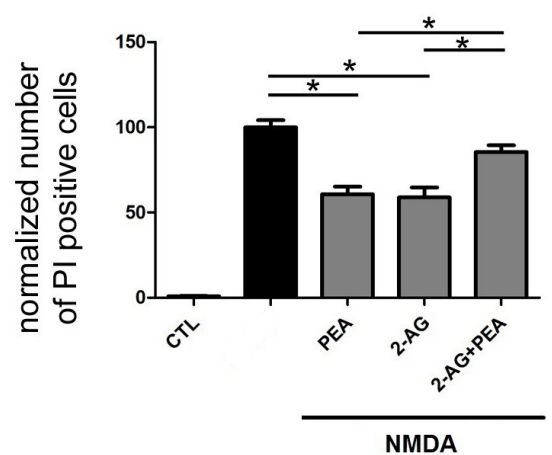

D

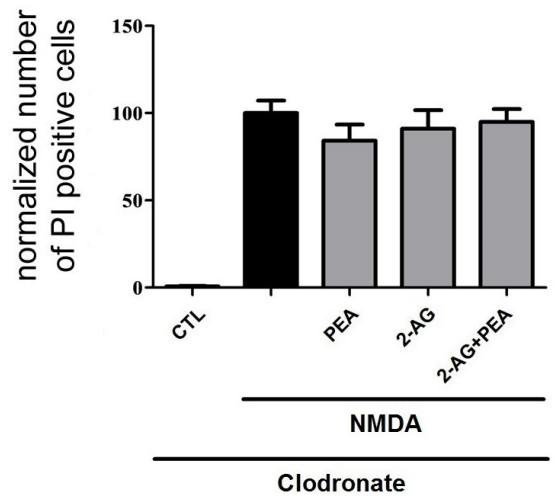

FIGURE 2 | Effects of 2-AG and PEA in excitotoxically damaged OHSC. 2-AG and PEA did not further decrease the number of PI positive degenerated neurons in comparison to OHSC treated with 2-AG or PEA alone.

(A) Treatment protocol. Control OHSC (CTL), were kept in culture medium and served as negative controls. The NMDA treated group function as positive control (NMDA). For microglial cells depleted groups clodronate (green) was applied from 1 div until 6 div. Cannabinoids were added alone on day 6 in vitro (Continued) 


\section{FIGURE 2 | Continued}

(div) to OHSC or following $4 \mathrm{~h}$ incubation with NMDA

(NMDA+2-AG/PEA/PEA+2-AG). The fixation was performed on 9 div. (B) Representative images of the dentate gyrus in OHSC stained with PI (in red). After NMDA damage a massive increase in the number of damaged neurons occurred in comparison to control group (CTL), PEA, and 2-AG significantly reduced the neurodegeneration, but combination of both did not significantly reduce the number of PI positive nuclei. Dentate gyrus (GD) is highlighted in blue, Cornu ammonis (CA) 3 in green. Scale bar $=50 \mu \mathrm{m}$. (C) Quantitative analysis of PI positive nuclei in treated groups. The number of PI positive neurons increased significantly after treatment with NMDA $\left(\mathrm{n}_{N M D A}=42\right)$ in comparison to control group $\left(\mathrm{n}_{C T L}=42\right)$. 2-AG, PEA alone or combination of both had no effect on viability of OHSC ( $n_{P E A}=12$,

$\left.\mathrm{n}_{2-A G}=12, \mathrm{n}_{2-A G+P E A}=10\right)$. Treatment with PEA ( $\left.\mathrm{n}_{N M D A+P E A}=23\right)$ or 2-AG $\left(\mathrm{n}_{N M D A+2-A G}=20\right)$ of excitotoxically damaged OHSC reduced significantly the number of PI positive cells. The combination of 2-AG and PEA after NMDA damage induced no significant protective effect $\left(\mathrm{n}_{N M D A}+2-A G+P E A=34\right)$. (D) Treatment of microglia depleted OHSC with NMDA induced a massive neuronal damage $\left(\mathrm{n}_{C T L}=15, \mathrm{n}_{N M D A}=18\right)$. The application of PEA, 2-AG or combination of both to clodronate treated NMDA damaged OHSC had no significant effect on the number of $\mathrm{PI}$ positive cells $\left(\mathrm{n}_{C L O+N M D A+2-A G}=12\right.$, $\left.\mathrm{n}_{C L O+N M D A+P E A}=12, \mathrm{n}_{C L O}+N M D A+2-A G+P E A=14\right)$. Statistics was performed using a One-Way ANOVA with Bonferroni post hoc analysis and significance was chosen for $p<0.05$. The asterisk denotes significant results regarding the respective measurement indicated with the bar. The values are served as a mean with standard error of the mean.

was applied for $1 \mathrm{~h}$. The following subsequent steps were the same as for $\mathrm{IB}_{4}$ staining: the cells were washed tree times with PBS and incubated with ExtrAvidin-Peroxidase for $1 \mathrm{~h}$. After washing with PBS and Tris buffer, the slides were stained with 3,3'Diaminobenzidine (DAB) (Sigma-Aldrich, cat No. D8001) and covered with Entallan (Merck Millipore, Darmstadt, Germany, cat No. 107960).

\section{Microscopy and Analysis}

For analysis of proliferation index, ramification index and PPAR $\alpha$ staining five areas per cover slip were recorded with Leica DMi8 (Wetzlar, Germany) or Axioplan (Zeiss, Oberkochen, Germany) microscopes.

Proliferation index was represented as the ratio of $\mathrm{BrdU}$ positive cells to all DAPI positive cells. The BrdU positive cells were counted using image J v1.46r (National Institutes of Health, Laboratory for Optical and Computational Instrumentation, University of Wisconsin, Madison, WI, United States).

To evaluate the ramification of microglial cells, the surface of microglia was stained with $\mathrm{IB}_{4}$ and the outlining of the cell was divided by the smallest convex hull around the cell. Values close to 1 correspond to strongly amoeboid cells while lower numbers represent ramified cells. The analysis was performed automatically using a self-written MatLab script (The MathWorks, Natick, MA, United States).

Next, the translocation of PPAR $\alpha$ from the cytoplasm to the nucleus or vice versa was assessed after treatment with cannabinoids. PPAR $\alpha$ staining was performed and manually evaluated by counting cells that showed a nuclear or/and cytoplasmic staining or were free of PPAR $\alpha$ labeling. Results are presented as proportion of cells with a specific expression pattern relative to the total number of cells. For the calculation of the standard error of the mean in these experiments we used bootstrapping to calculate empirical standard deviations. Therefore all measurements were used and resampled 10,000 times. Afterward, the proportion of nuclear, cytoplasmic, nuclear+cytoplasmic location or no expression was calculated for each resampling and an empirical standard deviation and standard error of the mean was calculated.

The imaging of the fixed OHSC was performed using a confocal laser scanning microscope (LSM 510 Meta, Zeiss) with an excitation wavelength of $488 \mathrm{~nm}$ for $\mathrm{IB}_{4}$ and $543 \mathrm{~nm}$ for PI. Emission was detected using a band-pass filter with $\Delta \lambda=510$ $550 \mathrm{~nm}\left(\mathrm{IB}_{4}\right)$ and $\Delta \lambda=610-720 \mathrm{~nm}(\mathrm{PI})$. The dentate gyrus was visualized with a $20 \mathrm{x}$ objective, as a $\mathrm{z}$-stack with a step width of $2 \mu \mathrm{m}$ (Grabiec et al., 2012). The number of PI positive death cells in the obtained image stacks was analyzed using the maximal intensity projection and quantified using a selfwritten Matlab script.

\section{Nitrite Assay}

A standard solution was prepared by solving sodium nitrite in medium up to concentrations of $100,50,25,12.5,6.25,3.125$, and $1.5625 \mu \mathrm{M}$. The measured values were used for calculation of a standard curve. $50 \mu \mathrm{l}$ of the standard solutions or $50 \mu \mathrm{l}$ of the collected samples were analyzed in duplicate. After applying $50 \mu \mathrm{l}$ of Griess reagent (Sigma-Aldrich) the extinction was measured after $15 \mathrm{~min}$ at $540 \mathrm{~nm}$ in a microplate reader (SynergyTM Mx, BioTek Instruments, Winooski, VT, United States). The nitrite concentrations for the samples were interpolated from the standard curves.

\section{Statistical Analysis}

Statistics was performed using the one-way ANOVA with Bonferroni post-test and significance was chosen for $p<0.05$. All $p$-values refer to the respective controls of the same parameter of the same cell line or to the treatment with agonist for the respective receptor. All groups were normalized to the positive

TABLE 1 | Antibodies.

\begin{tabular}{|c|c|c|c|c|}
\hline Name & Company & Number & Dilution & Antibody ID \\
\hline Biotinylated goat anti-rabbit antibody & Sigma-Aldrich & B7389 & $1: 100$ & \\
\hline BrdU & DAKO & M0744 & $1: 100$ & \\
\hline Alexa 488 conjugated $\mathrm{IB}_{4}$ & Molecular Probes, Life Technologies, Eggenstein, Germany & 121411 & $1: 500$ & AB_2314662 \\
\hline Biotin labeled $\mathrm{IB}_{4}$ & Vector Laboratories, Burlingame, CA, United States & B-1205 & $1: 100$ & AB_2314661 \\
\hline ExtrAvidin-Peroxidase & Sigma-Aldrich & E2886 & $1: 100$ & \\
\hline $\operatorname{PPAR} \alpha$ & Thermo Fisher, Waltham, MA, United States & PA1-822A & $1: 500$ & AB_2165595 \\
\hline
\end{tabular}


control. Statistics for cellular PPAR $\alpha$ was performed using a Chi Square test and significance was chosen for $p<0.05$. The values are served as a mean with standard error of the mean. The asterisk denotes significant results regarding the respective measurement indicated with the bar.

\section{RESULTS}

\section{2-AG and PEA Do Not Further Decrease the Number of PI Positive Degenerated Neurons}

The application of NMDA led to an increase in the number of PI positive cells in OHSC (100.0 $\pm 4.24 \%)$ in comparison to control group $(0.86 \pm 0.28 \%$, Figures $2 B, C)$.

Treatment of NMDA lesioned OHSC with PEA $(60.64 \pm 4.52 \%)$ or $2-\mathrm{AG}(58.78 \pm 5.94 \%)$ induced a significant reduction of neuronal damage. Combination of $2-\mathrm{AG}$ and PEA (85.46 $\pm 3.92 \%)$ in excitotoxically damaged OHSC did not decrease the number of dead cells in a significant manner (Figures 2B,C). Notably the values were not significantly different when compared to NMDA group, but significantly higher when compared to NMDA+2-AG or NMDA+ PEA groups.

\section{Depletion of Microglial Cells Leads to Loss of Neuroprotection}

The application of NMDA to microglia depleted OHSC (Figure 1) led to a significant increase in the number of PI positive cells $(100.0 \pm 7.12 \%)$ in comparison to control group $(0.74 \pm 0.17 \%$, Figure 2D). The depletion of microglial cells was controlled through $\mathrm{IB}_{4}$ staining (Figure 1).

Neither the application of PEA (84.19 $\pm 9.29 \%)$ nor 2AG $(91.04 \pm 10.68 \%)$ to NMDA damaged microglia depleted OHSC induced a significant neuroprotective effect. Also, the combination of $2-\mathrm{AG}$ and PEA $(94.93 \pm 7.42 \%)$ to excitotoxically damaged microglia depleted OHSC showed any significant effect on the number of dead neurons (Figure 2D).

\section{Effects of 2-AG and PEA Treatment on Ramification Index}

Application of PEA $(0.72 \pm 0.01)$ or 2 -AG $(0.75 \pm 0.02)$ had no impact on ramification index in comparison to control group $(0.73 \pm 0.01)$. Treatment with LPS $(0.89 \pm 0.01)$ led to a more amoeboid morphology of cells. Co-application of LPS and PEA reduced the ramification index significantly $(0.76 \pm 0.03)$ making cells more ramified. Incubation with $2-\mathrm{AG}$ did not change the ramification index $(0.84 \pm 0.01)$ in comparison to LPS. However, PEA and 2-AG application together with LPS induced significant reduction in ramification index $(0.76 \pm 0.02)$ (Figures 3A,C).

\section{Effects of 2-AG and PEA on Nitrite Concentration}

Application of PEA (0.19 $\pm 0.1 \%), 2-A G(0.14 \pm 0.06 \%)$, or PEA+2-AG $(0.76 \pm 0.30 \%)$ did not change the nitrite concentration in comparison to control group $(0.48 \pm 0.22 \%)$. Treatment with LPS $(100.0 \pm 2.24 \%)$ led to an increased concentration of nitrite. Whereas co-application of LPS and PEA reduced the nitrite concentration significantly $(81.06 \pm 4.6 \%)$, incubation with $2-\mathrm{AG}$ increased the nitrite concentration $(128.2 \pm 5.52 \%)$ in comparison to LPS. The same increase was detected for application of $2-\mathrm{AG}+$ PEA+ LPS $(134.5 \pm 7.11 \%)$ (Figure 3E).

\section{Effect of 2-AG and PEA on Proliferation of Primary Microglial Cells}

After incubation with LPS (0.07 \pm 0.01$)$, PEA (0.13 \pm 0.04$)$, or 2 -AG $(0.12 \pm 0.05)$ no significant changes in proliferation were detected in comparison to control group (0.097 \pm 0.02$)$. The results for PEA+2-AG (0.07 \pm 0.02$)$; LPS+PEA $(0.07 \pm 0.019)$; LPS+2-AG (0.09 \pm 0.05$)$; and LPS+PEA+2AG $(0.07 \pm 0.03)$ were not significantly altered after treatment (Figures 3B,D). The overall test showed no significant differences between the groups.

\section{PPAR $\alpha$ Distribution and Cellular Localization After Incubation With 2-AG and PEA}

The evaluation of the localization of the PPAR $\alpha$ receptor was significantly altered for treated groups overtime $(1,6,24 \mathrm{~h})$ (Figures 4A-E). The positive staining was localized in the cytoplasm and in the nucleus. The subcellular location was scored in 483 ( $1 \mathrm{~h}), 362(6 \mathrm{~h})$, and 337 (24 h) cells by light microscopy and presented as percentage. Each independent experiment was repeated at least three times $(n=3)$. The number of cells expressing nuclear as compared to cytoplasmic $\operatorname{PPAR} \alpha$ was significantly different between groups. Treatment with PEA; 2-AG; and LPS induced a significant shift in PPAR $\alpha$ distribution after 1 and $6 \mathrm{~h}$ from nuclear to cytoplasmic and from cytoplasmic to nuclear localization. PEA and LPS changed significantly the localization of the receptor after $24 \mathrm{~h}$ (Figures 4A-C). The distribution was significantly different between 2-AG (Nucleus, N: 36\%, Cytoplasm, C:21\%, Both, B:33\%, No signal, None:10\%) and 2-AG co-applied with PEA (N:50\%, C:4\%, B:43\%, None:4\%) after 1 h, between PEA (N:49\%, C:11\%, B:38\%, None:2\%) and 2-AG+PEA (N:22\%, C:11\%, B:51\%, None:16\%) after $6 \mathrm{~h}$ and between PEA (N:51\%, C:3\%, B:36\%, None: $10 \%)$ or $2-A G(N: 11 \%$, C:7\%, B:83\%, None: $0 \%)$ and 2-AG+PEA (N:29\%, C:2\%, B:66\%, None:2\%) after 24 h. PEA $\left(\mathrm{N}_{1 h}: 51 \%, \mathrm{C}_{1 h}: 5 \%, \mathrm{~B}_{1 h}: 17 \%\right.$, None ${ }_{h}: 27 \%$; N 6 $: 61 \%, \mathrm{C}_{6 h}: 7 \%$, $\mathrm{B}_{6} h: 18 \%$, None $\left.6 h: 14 \%\right), 2-\mathrm{AG}\left(\mathrm{N}_{1}{ }_{h}: 67 \%, \mathrm{C}_{1} h: 3 \%, \mathrm{~B}_{1 h}: 29 \%\right.$, None $_{1} h: 1 \% ; \mathrm{N}_{6} h: 30 \%, \mathrm{C}_{6} h: 11 \%, \mathrm{~B}_{6} h: 34 \%$, None $\left.6 h: 26 \%\right)$ and PEA+2-AG $\left(\mathrm{N}_{1} h: 54 \%, \mathrm{C}_{1}{ }_{h}: 14 \%, \mathrm{~B}_{1}{ }_{h}: 20 \%\right.$, None $_{1}: 12 \%$; $\left.\mathrm{N}_{6 h}: 21 \%, \mathrm{C}_{6 h}: 21 \%, \mathrm{~B}_{6 h}: 35 \%, \mathrm{NS}_{6}: 23 \%\right)$ changed significantly the localization of PPAR $\alpha$ after 1 and $6 \mathrm{~h}$ in combination with LPS (vs. LPS; $\mathrm{N}_{1} h_{2}: 25 \%, \mathrm{C}_{1} h_{h}: 15 \%, \mathrm{~B}_{1} h: 53 \%$, None ${ }_{1}: 7 \%$; $\mathrm{N}_{6}{ }_{h}: 67 \%, \mathrm{C}_{6}{ }_{h}: 10 \%, \mathrm{~B}_{6}{ }_{h}: 20 \%$, None $\left._{6}{ }: 3 \%\right)$. No effect could be observed for LPS+PEA (N: 22\%, C: 3\%, B: 69\%, None: 6\%) in comparison to LPS (N: $28 \%, \mathrm{C}$ : $2 \%, \mathrm{~B}: 56 \%$, None: $14 \%$ ) after $24 \mathrm{~h}$, but $2-\mathrm{AG}$ (N: 27\%, C: $2 \%$, B: $69 \%$, None: $2 \%$ ) and 2-AG+PEA (N: 20\%, C: 0\%, B: 80\%, None: 0\%) if co-applied 
A
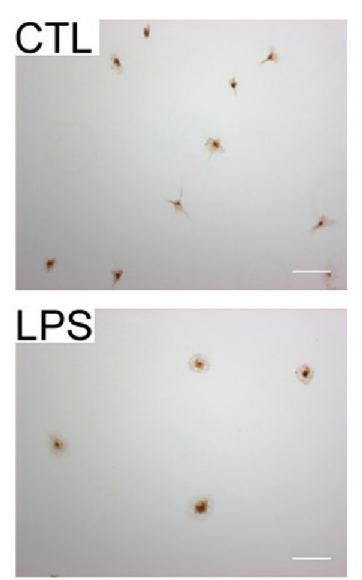

B
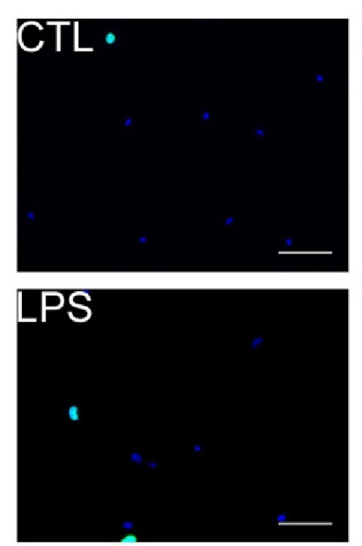

C

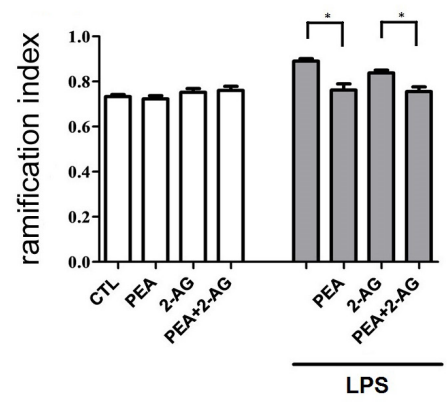

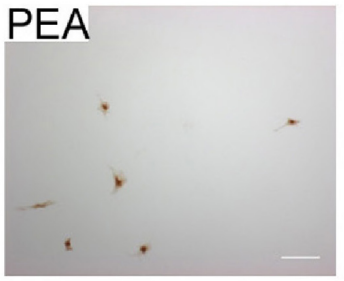
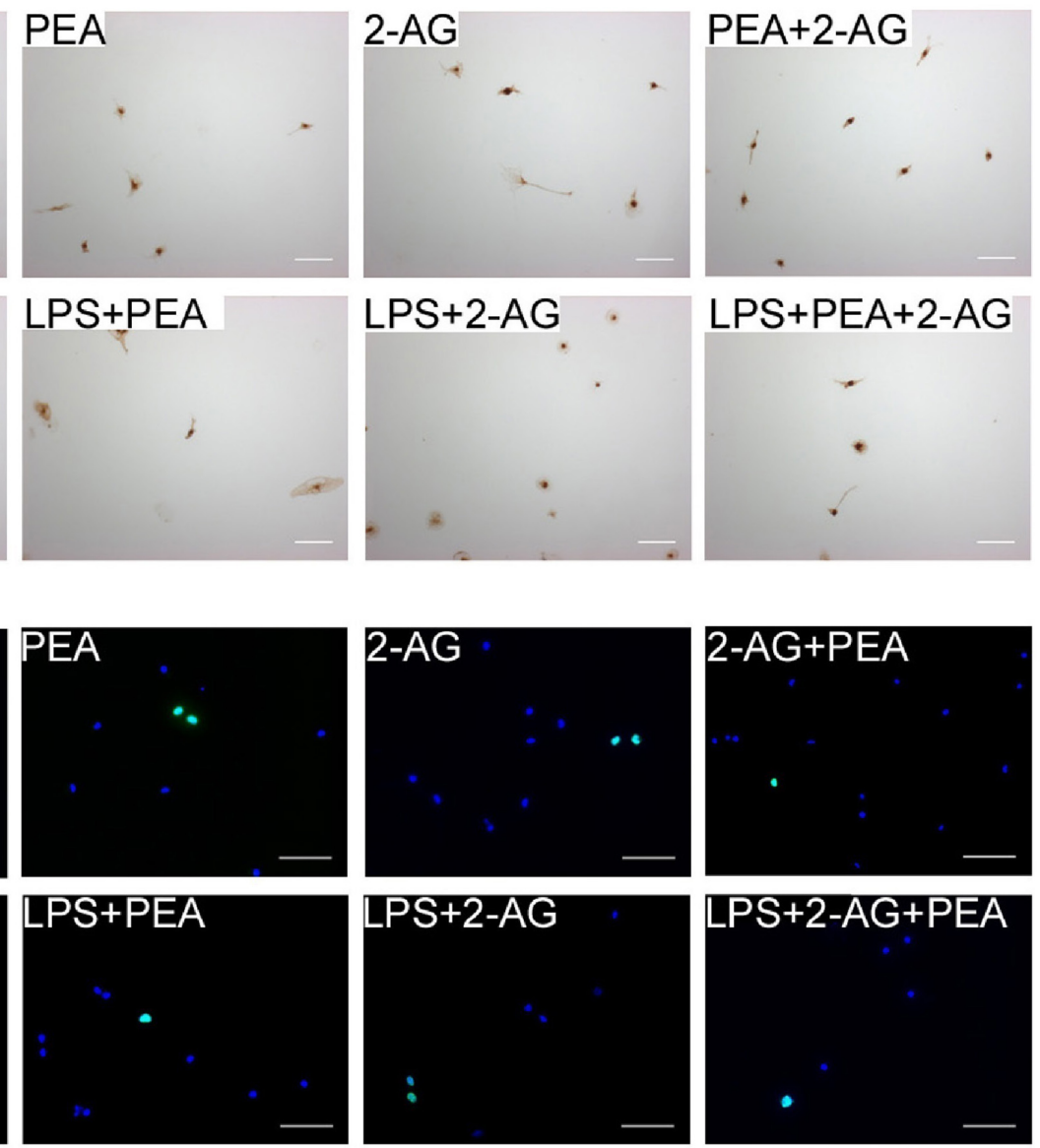

E
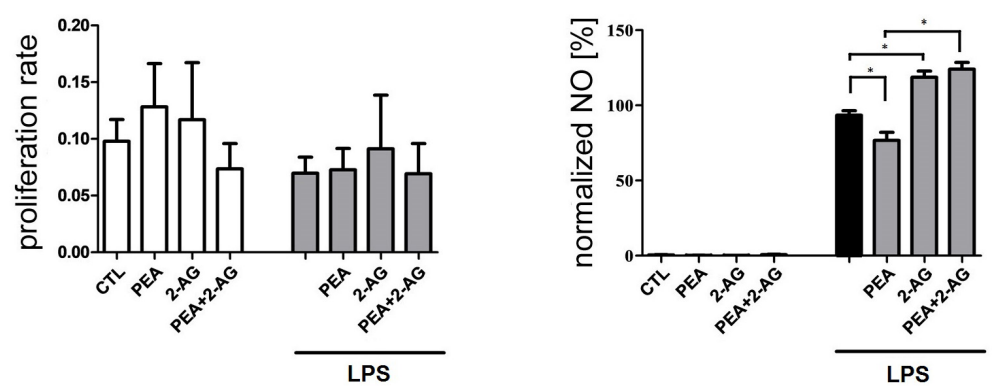

FIGURE 3 | Effect of 2-AG and PEA on ramification index, proliferation index and nitrite concentration of primary rat microglia. Representative pictures of stained microglia for $(\mathbf{A})$ ramification index $\left(\mathrm{IB}_{4}\right)$ and $\mathbf{( B )}$ proliferation rate (BrdU in green, DAPI in blue). Scale bar $=50 \mu \mathrm{m}$. (C) Effects of 2-AG and PEA on ramification index. Application of LPS ( $\mathrm{n}_{L P S}=22$ ) led to an increase in the ramification index in comparison to control group $\left(C T L ; \mathrm{n}_{C T L}=22\right)$. Whereas PEA co-applied with LPS $\left(\mathrm{n}_{L P S}+P E A=23\right)$ reduced the ramification index significantly, 2-AG ( $\left.\mathrm{n}_{L P S}+2-A G=23\right)$ had no effect. 2-AG, PEA, or combination of both applied alone ( $\mathrm{n}_{P E A}=19$, $\left.\mathrm{n}_{2-A G}=22, \mathrm{n}_{2-A G+P E A}=22\right)$ had no effect on ramification index. The combination of $L P S, 2-A G$ and $P E A\left(n_{L P S}+2-A G+P E A=22\right)$ led to decrease in the ramification index in comparison to the groups treated with LPS and 2-AG. (D) No effect of 2-AG and PEA with/or without LPS on proliferation of primary microglia cells could be observed $\left(\mathrm{n}_{C T L}=12, \mathrm{n}_{L P S}=12, \mathrm{n}_{P E A}=11, \mathrm{n}_{2-A G}=11, \mathrm{n}_{2-A G+P E A}=12, \mathrm{n}_{L P S}+P E A=12, \mathrm{n}_{L P S}+2-A G=11, \mathrm{n}_{L P S}+2-A G+P E A=12\right) .(\mathrm{E})$ Effects of 2-AG and PEA on nitrite concentration after $72 \mathrm{~h}$. PEA, 2-AG, or PEA combined with 2-AG had no effect on the nitrite concentration in primary microglia $\left(\mathrm{n}_{C T L}=18\right.$, $\mathrm{n}_{P E A}=18$,

$\left.\mathrm{n}_{2-A G}=18, \mathrm{n}_{2-A G+P E A}=18\right)$. After administration of LPS, nitrite concentration increased significantly. PEA co-applied with LPS ( $\left.\mathrm{n}_{L P S}+P E A=18\right)$ decreased the NO production in comparison to LPS ( $\left.n_{L P S}=18\right)$. 2-AG+LPS $\left(n_{L P S}+2-A G=18\right)$ and also 2-AG+PEA+LPS ( $(n L P S+2-A G+P E A=18)$ treated microglia produced significantly more NO in comparison to LPS. Statistics was performed using a one-way ANOVA test with Bonferroni correction and significance was chosen for $p<0.05$. The asterisk denotes significant results regarding the respective measurement indicated with the bar. The values are served as a mean with standard error of the mean. 

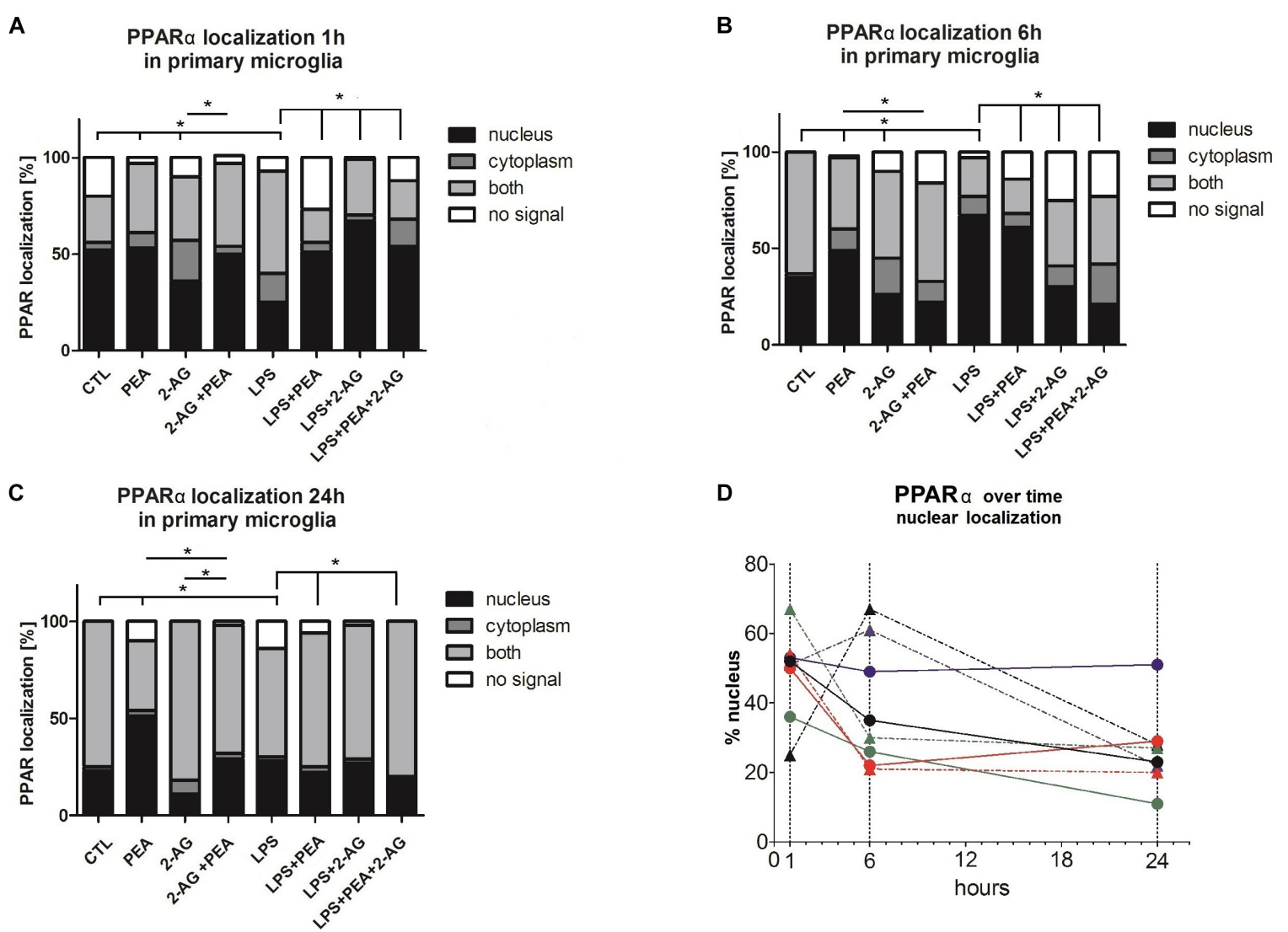

E

PPAR a over time cytoplasmic localization

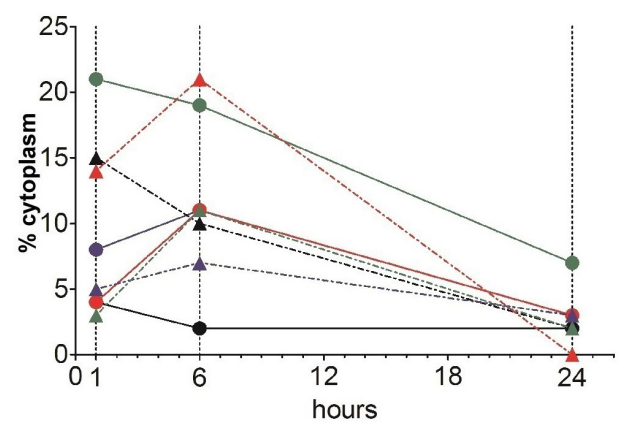

- CTL

- PEA

- 2-AG

- 2-AG +PEA

- LPS

$\star$ LPS+PEA

- LPS+2-AG

- LPS+PEA+2-AG

FIGURE 4 | PPAR $\alpha$ subcellular distribution and cellular localization after incubation with 2-AG and PEA in primary microglial cells. The localization of PPAR $\alpha$ was analyzed over time by the use of staining (A-C) 1, 6, and $24 \mathrm{~h}$ after treatment, (D) nuclear, (E) cytoplasmic localization (1, 6, and $24 \mathrm{~h}$ after treatment). The number of cells which did not or expressed PPAR $\alpha$ in the nucleus or/and cytoplasm was counted. In graphs (A-E) the subcellular location was scored in 483 (1 h), 362 (6 h), and $337(24 \mathrm{~h})$ cells by light microscopy and presented as percentage. Each independent experiment was repeated at least three times. The same data are displayed in two different ways to point out the differences in the distribution (A-C) between the time points for cytoplasmic and nuclear localization (D,E). Statistics was performed using a Chi Square test and significance was chosen for $p<0.05$. The asterisk denotes significant results regarding the respective measurement indicated with the bar. The values are served as a mean with standard error of the mean.

with LPS altered significantly the distribution (Figures 4A-C and Table 2).

Lipopolysaccharide alone induced a shift to nuclear localization after $6 \mathrm{~h}$, whereas LPS+PEA+2-AG after $6 \mathrm{~h}$ led to more cytoplasmic expression, similar to 2-AG and PEA alone (Figures 4D,E).

\section{DISCUSSION}

Reduction of neuronal damage in injured patients is a main contributor to sustain quality of life, for this reason its improvement and new approaches are needed. Evidence has accumulated that endocannabinoids can be beneficial for 


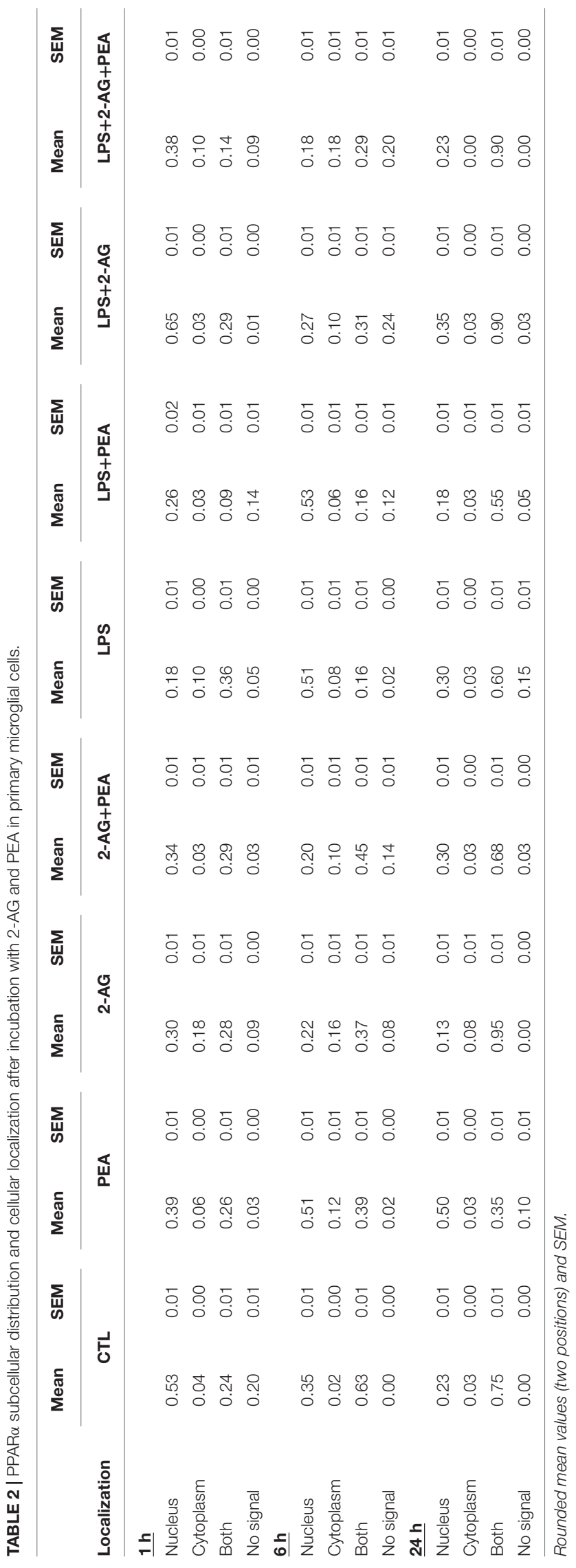

treatment of patients with brain injury (Fernandez-Ruiz et al., 2010). Cannabinoids, as shown before have different targets and are potential therapeutics, but first it is necessary to better understand the molecular and cellular mechanisms of cannabinoid action.

\section{The Protective Effects of 2-AG and PEA Are Abolished, When Both Are Applied Together}

In this study, we focused on excitotoxicity, a main factor of neuronal damage as described before (Kunz et al., 2010; Lau and Tymianski, 2010). To investigate the intrinsic responses and to exclude interfering influences such as blood flow and infiltrating peripheral immune cells the well-established model of excitotoxic lesioned OHSC was chosen. Both, PEA and 2-AG were shown to be protective with microglia participation in NMDA lesioned OHSC before. In our previous studies we extensively examined the involvement of cannabinoid receptors in PEA and 2-AG mediated actions. Whereas PEA and the synthetic PPAR $\alpha$ agonist $\mathrm{Wy}-14,643$ protected dentate gyrus granule cells, treatment with the PPAR $\alpha$ antagonist GW6471 blocked PEA-mediated neuroprotection. Selective activation or inhibition of PPAR $\gamma$ displayed no positive effect (Koch et al., 2011a). Interestingly, 2-AG induced neuroprotection was inhibited by cannabidiol (CBD) and O-1918 and mimicked by abn-CBD indicating the involvement of abn-CBDR. The 2-AG effects were not blocked by the specific $\mathrm{CB}_{2}$ receptor antagonist (AM630). Depletion of microglial cells abolished the neuroprotection mediated by $2-\mathrm{AG}$ or abn-CBD raising the hypothesis that the neuroprotective effects of 2-AG were abnCBDR and microglia dependent (Kreutz et al., 2007, 2009). The abn-CBDR is a pharmacologically characterized non- $\mathrm{CB}_{1} /$ non$\mathrm{CB}_{2}$ receptor and has been first described on endothelial cells of rat mesenteric blood vessels (Járai et al., 1999; Pertwee et al., 2010), and has not been identified yet. PEA, 2-AG or their analogs were also protective in other models like moderate traumatic injury and reduced neuroinflammation (Panikashvili et al., 2001; Genovese et al., 2008; D’Agostino et al., 2012; Esposito et al., 2012; Mounsey et al., 2015; Guida et al., 2017; Belardo et al., 2019; Impellizzeri et al., 2019). In PPAR $\alpha^{-/-}$ mice PEA induced neuroprotection after spinal cord trauma was abolished, however involvement of further PPARs was suggested (Paterniti et al., 2013). The application of PEA was found to trigger the synthesis of $2-A G$ in human and canine plasma and enhance its effects on transient receptor potential cation channel subfamily V member 1 (TRPV1) in HEK-293 cells (Petrosino et al., 2016). In striatum PEA triggered the synthesis of 2-AG via GPR55 (Musella et al., 2017). These effects were referred to an entourage effect, which might be mediated through TRPV1 activation or inhibition of fatty acid amide hydrolase, with PEA as its substrate or activation of GPR55 (Jonsson et al., 2001; Smart et al., 2002). A further possible explanation is an allosteric modulation, which could explain that 2-AG and PEA abolished their neuroprotective properties in the OHSC model and reduced ramification index at PEA level. While TRPV1 was not found in OHSC, GPR55 
was expressed in slices and was associated with neuroprotection (Grabiec et al., 2012; Kallendrusch et al., 2013). Consequently, GPR55 might be involved in the PEA mediated actions observed here. Furthermore, PEA was also shown to enhance the $\mathrm{CB}_{2}$ expression via PPAR $\alpha$ activation in macrophages (Guida et al., 2017). Increased number of $\mathrm{CB}_{2}$ next to abn-CBDR can be activated by $2-\mathrm{AG}$ and induce further effects. PEA at cellular level reduced ramification index, making cells more ramified whereas 2-AG had no impact on morphology of microglial cells. The decrease in neuroprotection mediated by co-treatment with both cannabinoids might be attributable to their effects on cellular level, especially on microglial cells, the conductor of the neuroprotective properties of 2-AG and PEA. An entourage effect with PEA as enhancer of the anti-inflammatory and anti-nociceptive activity of other endogenous compounds by potentiating their affinity for a receptor or by inhibiting their metabolic degradation (Skaper and Facci, 2014) is missing in OHSC in the context of neuroprotection.

\section{Effects of PEA and 2-AG Are Microglia Dependent}

Neuroprotective capabilities of microglial cells include synaptic stripping, induction of neurogenesis, phagocytosis, and maintenance of central nervous system homeostasis (Chen and Trapp, 2016). On the other hand microglial cells are also able to suppress neuroinflammation, protect nerve tissue by producing anti-inflammatory and tissue-repairing cytokines and factors (Colton, 2009). Microglial cells can contribute to neuronal damage via inflammation and release of cytotoxic substances as described earlier and are associated with neurodegenerative diseases, cognitive dysfunction in aging and dementia, epilepsy, and other conditions leading to brain inflammation and neuronal lesion (Ekdahl et al., 2003; Smith et al., 2012; Chhor et al., 2013). Cannabinoids were shown to interact with microglial cells in further pathological states and to change the morphology, activation and number of the cells (Zhang et al., 2003; Luongo et al., 2010; Guida et al., 2017).

After microglia depletion in OHSC with the bisphosphonate clodronate PEA and 2-AG lost their neuroprotective effects supporting the hypothesis that 2-AG, PEA exert their neuroprotective effects via microglial cells. PEA was shown before to induce migration and increase of motility of BV2 microglial cell line (Franklin et al., 2003; Guida et al., 2017). Notably, microglial cells produce both 2-AG and PEA (Muccioli et al., 2007; Muccioli and Stella, 2009) and their levels were found to be increased after focal cerebral ischemia (Franklin et al., 2003).

\section{PEA and 2-AG Mediate Opposite Effects on Nitric Oxide Synthesis in Primary Microglial Cells}

Endocannabinoids, which are in part produced by microglia, affect the ability of microglia cells to proliferate, phagocytize, and produce NO (Stella, 2009). NO production occurs enzymatically via a conversion of L-arginine to L-citrulline by $\mathrm{NO}$ synthase, competing with arginase for L-arginine as a substrate. iNOS is not expressed in healthy brain tissue under physiological conditions but its expression can be induced in astrocytes and microglial cells through trauma. iNOS induction starts several hours before $\mathrm{NO}$ is generated and involves transcription of mRNA and novel protein synthesis. iNOS is mainly expressed under inflammatory conditions and after transient ischemic periods and is known as an antimicrobial defense mechanism of the immune system (Vincent et al., 1998). The increase in NO driven by iNOS might be neurotoxic as it forms reactive nitrogen oxide species like peroxynitrite (Garry et al., 2015). It was reported that $2-A G$ alone stimulates the release of NO from human immune and vascular tissues and from invertebrate immune cells via $\mathrm{CB}_{1}$ activation (Stefano et al., 2000). Contrary, in our study 2-AG or PEA applied alone had no effect on NO production by microglial cells after $72 \mathrm{~h}$. However, LPS in combination with 2-AG increased NO concentration, although 2-AG was protective after NMDA damage. PEA was able to reduce NO production by microglial cells after LPS treatment. In accordance to this study PEA significantly inhibited the NO release induced by LPS in murine macrophage cell line RAW264.7, which was not sensitive to pertussis toxin treatment, indicating a G-protein independent mode of action (Ross et al., 2000). Pre-treatment of LPSstimulated primary mouse microglial cells with PPAR $\alpha$ agonists also resulted in inhibition of NO production (Xu et al., 2005). In similarity to PEA in murine macrophage cell line RAW264.7, WIN55,212, a neuroprotective cannabinoid decreased NO level when applied together with LPS via $\mathrm{CB}_{2}$ receptor (Ross et al., 2000; Koch et al., 2011b). Furthermore, PEA reduced iNOS expression in spinal cord $6 \mathrm{~h}$ after paw edema induction (D’Agostino et al., 2007). The results presented in our study are in accordance with previous investigations and strengthen the hypothesis that PEA mediates neuroprotection via microglial cells. The neuroprotective effects observed here in the OHSC model underline the intrinsic positive effects of cannabinoids as influences through alterations in cerebral blood flow and infiltration of peripheral cells are missing (Grabiec et al., 2017), making the inhibition of NO produced by microglial cells one possible explanation for neuroprotection. In agreement with our work and previous studies LPS induces NO production mainly in microglial cells in models of excitotoxicity or during transient ischemic periods (Nakamura et al., 1999; Genovese et al., 2008; Yao et al., 2017). Further endocannabinoids were shown to decrease iNOS activity in rat microglial cells, e.g., CP55940 exerted a dose-dependent inhibition of interferon gamma /LPS-inducible NO production (Cabral et al., 2001) Little is known about the influence of endocannabinoids on arginase, in peripheral immune cells and in microglial N9 cells $\Delta$-9- tetrahydrocannabinol and $\mathrm{CB}_{2}$ agonist induced arginase 1 expression, what reduce NO production (Hegde et al., 2010; Ma et al., 2015).

Through combination treatment of both PEA and 2-AG, NO production was significantly elevated and neuroprotective properties were diminished. It leads to the hypothesis that PEA may be neuroprotective through reduction of NO present after brain injury. On the other hand, 2-AG significantly elevated NO production while still exerting neuroprotective effects similar 
to NO donors (Kakizawa et al., 2007), 2-AG acts probably via another targets and mechanisms.

\section{Changes in Morphology and Phenotypes of Primary Microglial Cells After Treatment}

In vivo, ex vivo, and in vitro a broad spectrum of differentiation stages of microglial cells has been observed (Dubbelaar et al., 2018). Under physiological conditions microglial cells are ramified and constantly scanning their surroundings (Nimmerjahn et al., 2005). Upon damage or inflammation, they become amoeboid, move to the site of neuronal lesion and remove cell debris. However, this morphological change of microglia upon a shift in activation state does not seem to be uniform, but it can be best mimicked by administration of LPS. The morphology ranges from amoeboid-like shapes during inflammation to highly ramified ones and includes many intermediate forms that are often associated with the activation status of microglial cells (Zhou et al., 2017; Dubbelaar et al., 2018). According to the phenotype microglial cells were often described as anti-inflammatory or neuroprotective or proinflammatory and neurotoxic. However, there is no binary system of phenotypes for microglia and they may possess multiple context dependent properties at the same time (Ransohoff, 2016; Dubbelaar et al., 2018).

In synopsis with NO reduction, the administration of PEA to LPS stimulated microglial cells induced a more ramified morphology; these anti-inflammatory properties of PEA may mediate its neuroprotective effects. 2-AG did not alter the LPS induced amoeboid state of microglial cells but increased the NO concentration, indicating that the neuroprotective properties of $2-\mathrm{AG}$ are mediated through other microglial cell dependent mechanisms than those involving NO. However, in vivo and in acute experimental autoimmune encephalomyelitis 2-AG increased the ramification of microglia (Lourbopoulos et al., 2011). In excitotoxically lesioned OHSC 2-AG reduced the number of microglial cells (Kreutz et al., 2007). It is plausible that the absence of changes is model dependent or that 2-AG influenced other properties of microglia, which were not examined in this study, like phagocytosis, motility, and alterations in extracellular signaling.

The combination of 2-AG and PEA induced a ramification of microglial cells in comparison to 2-AG and abolished PEA mediated NO concentration decrease. This may indicate that the anti-inflammatory properties of PEA are lost if co-incubated with $2-A G$, since decrease in the number of damaged neurons in OHSC was missing and therefore neuroprotection. 2-AG and PEA exert contrary effects on microglial cells and it is plausible, that co-application of both led to their abolishment. Expected entourage effect is missing in case of this model and those substances.

It will be necessary to verify how 2-AG exerts neuroprotection at a cellular level and whether this process is microglia dependent only, since 2-AG was found protective in isolated neuronal cultures (Zhang and Chen, 2008). Interestingly, proliferation of pure microglial cell cultures was not affected in this study, whereas the number of microglial cells was significantly decreased in dentate gyrus in OHSC after excitotoxical damage and treatment with PEA or 2-AG, this effect was mimicked by $\operatorname{PPAR} \alpha$ agonists and blocked by its antagonists (Kreutz et al., 2007; Koch et al., 2011a). Since microglial cells in culture proliferate very slowly without astrocytes, it seems plausible that the effects observed in OHSC might be the result of PEA actions on astrocytes, microglia, possibly neurons in the network and/or their cross-talk, since all cell types express the PPAR $\alpha$ receptor (Xu et al., 2006; Warden et al., 2016).

\section{PPAR $\alpha$ Expression and Localization Changed After Incubation With Cannabinoids}

Peroxisome proliferator-activated receptors predominantly are localized in the nucleus, theirs activity is modulated via phosphorylation and $\operatorname{PPAR} \alpha$ undergoes ligand-dependent nucleo-cytoplasmic shuttling (Burns and Vanden Heuvel, 2007; Umemoto and Fujiki, 2012). The amount of PPAR $\alpha$ was shown to increase in microglial cells in nucleus after $6 \mathrm{~h}$ and to decrease after $24 \mathrm{~h}$ after PEA treatment. PPARs are ligand-activated transcription factors, and their biological role is coupled to the function of their target genes. In immunocytochemical staining a translocation of PPAR $\alpha$ into the nucleus was seen. Neuroprotective effects of PEA are known to be mediated by PPAR $\alpha$. On the one hand, the nuclear localization of the receptor induces specific PEA related effects; its shift into the cytoplasm reduces the amount of available receptor in the nucleus. On the other hand the cytoplasmic localization of PPAR $\alpha$ may favor the binding of other ligands and mediate different actions (Guida et al., 2017). The lower levels of PPAR $\alpha$ in nuclei of microglial cells after simultaneous treatment with 2-AG and PEA with or without LPS might be a possible explanation for the missing neuroprotection in OHSC. It also indicates an interference between 2-AG and PEA signaling pathways with a more dominant role of 2-AG and inhibitory actions on PPARs translocation into the nucleus. Specific activation of central $\operatorname{PPAR} \alpha$ controls inflammation in the spinal cord as well as in the periphery (D'Agostino et al., 2007), when the amount of receptor decreased no effect could be induced. Additionally, fatty acid oxygenase metabolism products of 2-AG were able to activate $\operatorname{PPAR} \alpha$ receptor in human undifferentiated epidermal keratinocytes and stimulation of PPAR $\alpha$ and its downstream target genes led to cell differentiation (Kömüves et al., 2000; Kozak et al., 2002). It is plausible that 2-AG and PEA interact directly on $\operatorname{PPAR} \alpha$ receptor in the opposite way.

\section{CONCLUSION}

While endocannabinoids are promising regarding treatment of neuronal diseases, and their neuroprotective properties are known for a while, little is known how they are mediated. 2AG and PEA are both protective agents with different targets. Their positive effect is not enhanced by co-incubation. The understanding of interactions between signaling pathways of 
different endocannabinoids will help to elucide the in part conflicting results reported in the literature.

\section{DATA AVAILABILITY STATEMENT}

All datasets generated for this study are included in the article/supplementary material.

\section{ETHICS STATEMENT}

The animal study was reviewed and approved by the local authorities of the State of Saxony-Anhalt (permission number: I11M18, date: 01.12.2012) protecting animals and regulating tissue collection used for scientific purposes.

\section{REFERENCES}

Beggiato, S., Borelli, A. C., Ferraro, L., Tanganelli, S., Antonelli, T., and Cristina Tomasini, M. (2018). Palmitoylethanolamide blunts activation and improves neuronal survival in primary mouse cortical astrocytesneuron co-cultures. J. Alzheimer's Dis. 61, 389-399. doi: 10.3233/JAD-17 0699

Belardo, C., Iannotta, M., Boccella, S., Rubino, R. C., Ricciardi, F., Infantino, R., et al. (2019). Oral cannabidiol prevents allodynia and neurological dysfunctions in a mouse model of mild traumatic brain injury. Front. Pharmacol. 10:352. doi: 10.3389/fphar.2019.00352

Ben-Shabat, S., Fride, E., Sheskin, T., Tamiri, T., Rhee, M.-R., Vogel, Z., et al. (1998). An entourage effect: inactive endogenous fatty acid glycerol esters enhance 2-arachidonoyl-glycerol cannabinoid activity. Eur. J. Pharmacol. 353, 23-31. doi: 10.1016/s0014-2999(98)00392-6

Bruce, A. J., Sakhi, S., Schreiber, S. S., and Baudry, M. (1995). Development of kainic acid and N-methyl-d-aspartic acid toxicity in organotypic hippocampal cultures. Exp. Neurol. 132, 209-219. doi: 10.1016/0014-4886(95)90 026-8

Burns, K. A., and Vanden Heuvel, J. P. (2007). Modulation of PPAR activity via phosphorylation. Biochim. Biophys. Acta 1771, 952-960. doi: 10.1016/j.bbalip. 2007.04.018.Modulation

Cabral, G. A., Harmon, K. N., and Carlisle, S. J. (2001). "Cannabinoidmediated inhibition of inducible nitric oxide production by rat microglial cells: evidence for receptor participation," in Neuroimmune Circuits, Drugs of Abuse, and Infectious Diseases, eds H. Friedman, T. W. Klein, and J. J. Madden (Boston, MA: Springer), 207-214. doi: 10.1007/0-306-4761 1-8_24

Calignano, A., Rana, G., La Giuffrida, A., and Piomelli, D. (1998). Control of pain initiation by endogenous cannabinoids. Nature 394, 277-281. doi: 10.1038/ 28393

Carrier, E. J., Kearn, C. S., Barkmeier, A. J., Breese, N. M., Yang, W., Nithipatikom, K., et al. (2004). Cultured rat microglial cells synthesize the endocannabinoid 2-arachidonylglycerol, which increases proliferation via a CB 2 receptordependent mechanism. Mol. Pharmacol. 65, 999-1007. doi: 10.1124/mol.65. 4.999

Chen, Z., and Trapp, B. D. (2016). Microglia and neuroprotection. J. Neurochem. 136, 10-17. doi: 10.1111/jnc.13062

Chhor, V., Le, T., Lebon, S., Oré, M.-V., Celador Lara, I., Josserand, J., et al. (2013). Brain, behavior, and immunity characterization of phenotype markers and neuronotoxic potential of polarised primary microglia in vitro. Brain Behav. Immun. 32, 70-85. doi: 10.1016/j.bbi.2013.02.005

Citraro, R., Russo, E., Scicchitano, F., Rijn, C. M., Van Cosco, D., Avagliano, C., et al. (2013). Neuropharmacology Antiepileptic action of $\mathrm{N}$ palmitoylethanolamine through CB1 and PPAR- a receptor activation in

\section{AUTHOR CONTRIBUTIONS}

FD and UH: conceptualization, supervision, and project administration. $\mathrm{MP}, \mathrm{UH}, \mathrm{TH}$, and $\mathrm{JK}$ : methodology and formal analysis. TH: software and data curation. MP, UH, TH, and FD: validation. MP, UH, JK, TH, and CG: investigation. FD: resources. $\mathrm{UH}$ and $\mathrm{MP}$ : visualization and writing original draft. $\mathrm{UH}, \mathrm{TH}, \mathrm{JK}$, and FD: writing review and editing. All authors contributed to the manuscript revision, and read and approved the submitted version.

\section{FUNDING}

We acknowledge the financial support within the funding program Open Access Publishing by the German Research Foundation (DFG).

a genetic model of absence epilepsy. Neuropharmacology 69, 115-126. doi: 10.1016/j.neuropharm.2012.11.017

Colton, C. A. (2009). Heterogeneity of microglial activation in the innate immune response in the brain. J. Neuroimmune. Pharmacol. 4, 399-418. doi: 10.1007/ s11481-009-9164-4

D’Agostino, G., Rana, G., La Russo, R., Sasso, O., Iacono, A., Esposito, E., et al. (2007). Acute intracerebroventricular administration of palmitoylethanolamide, an endogenous peroxisome proliferator-activated receptor-alpha agonist, modulates carrageenan-induced paw edema in mice. J. Pharmacol. Exp. Ther. 332, 1137-1143. doi: 10.1124/jpet.107.12 3265

D’Agostino, G. D., Russo, R., Avagliano, C., Cristiano, C., Meli, R., and Calignano, A. (2012). Palmitoylethanolamide protects against the amyloid- B 25-35induced learning and memory impairment in mice, an experimental model of alzheimer disease. Neuropsychopharmacology 37, 1784-1792. doi: 10.1038/npp. 2012.25

Dirnagl, U., Simon, R. P., and Hallenbeck, J. M. (2003). Ischemic tolerance and endogenous neuroprotection. Trends Neurosci. 26, 248-254. doi: 10.1016/ S0166-2236(03)00071-7

Dubbelaar, M. L., Kracht, L., Eggen, B. J. L., and Boddeke, E. W. G. M. (2018). The kaleidoscope of microglial phenotypes. Front. Immunol. 9:1753. doi: 10.3389/ fimmu.2018.01753

Ebrahimi, F., Hezel, M., Koch, M., Ghadban, C., Korf, H. W., and Dehghani, F. (2010). Analyses of neuronal damage in excitotoxically lesioned organotypic hippocampal slice cultures. Ann. Anat. 192, 199-204. doi: 10.1016/j.aanat.2010. 06.002

Ekdahl, C. T., Claasen, J., Bonde, S., Kokaia, Z., and Lindvall, O. (2003). Inflammation is detrimental for neurogenesis in adult brain. PNAS 100, 1363213637.

Esposito, E., Impellizzeri, D., Mazzon, E., Paterniti, I., and Cuzzocrea, S. (2012). Neuroprotective activities of palmitoylethanolamide in an animal model of parkinson's disease. PLoS One 7:e41880. doi: 10.1371/journal.pone.0041880

Facchinetti, F., Del Giudice, E., Furegato, S., Passarotto, M., and Leon, A. (2003). Cannabinoids ablate release of TNFalpha in rat microglial cells stimulated. Glia 41, 161-168. doi: 10.1002/glia.10177

Fernandez-Ruiz, J., Garcia, C., Sagredo, O., Gomez-Ruiz, M., and de Lago, E. (2010). The endocannabinoid system as a target for the treatment of neuronal damage. Expert Opin. Ther. Targets 14, 387-404. doi: 10.1517/ 14728221003709792

Fernández-Ruiz, J., Moro, M. A., and Martínez-Orgado, J. (2015). Cannabinoids in neurodegenerative disorders and stroke / brain trauma: from preclinical models to clinical applications. Neurotherapeutics 12, 793-806. doi: 10.1007/s13311015-0381-7

Franklin, A., Parmentier-batteur, S., Walter, L., Greenberg, D. A., and Stella, N. (2003). Palmitoylethanolamide increases after focal cerebral ischemia and 
potentiates microglial cell motility. J. Neurosci. 23, 7767-7775. doi: 10.1523/ jneurosci.23-21-07767.2003

Franklin, A., and Stella, N. (2003). Arachidonylcyclopropylamide increases microglial cell migration through cannabinoid CB 2 and abnormalcannabidiol-sensitive receptors. Eur. J. Pharmacol. 474, 195-198. doi: 10.1016/ S0014-2999(03)02074-0

Garry, P. S., Ezra, M., Rowland, M. J., Westbrook, J., and Pattinson, K. T. S. (2015). The role of the nitric oxide pathway in brain injury and its treatment - From bench to bedside. Exp. Neurol. 263, 235-243. doi: 10.1016/j.expneurol.2014. 10.017

Genovese, T., Esposito, E., Mazzon, E., Paola, R., Di Meli, R., Bramanti, P., et al. (2008). Effects of palmitoylethanolamide on signaling pathways implicated in the development of spinal cord injury. J. Pharmacol. Exp. Ther. 326, 12-23. doi: 10.1124/jpet.108.136903.recent

Grabiec, U., Hohmann, T., Hammer, N., and Dehghani, F. (2017). Organotypic hippocampal slice cultures as a model to study neuroprotection and invasiveness of tumor cells. J. Vis. Exp. 126:e55359. doi: 10.3791/ 55359

Grabiec, U., Koch, M., Kallendrusch, S., Kraft, R., Hill, K., Merkwitz, C., et al. (2012). The endocannabinoid $\mathrm{N}$-arachidonoyldopamine (n.d.) exerts neuroprotective effects after excitotoxic neuronal damage via cannabinoid receptor 1 (CB 1). Neuropharmacology 62, 1797-1807. doi: 10.1016/j. neuropharm.2011.11.023

Guida, F., Luongo, L., Boccella, S., Giordano, M. E., Romano, R., Bellini, G., et al. (2017). Palmitoylethanolamide induces microglia changes associated with increased migration and phagocytic activity: involvement of the CB2 receptor. Sci. Rep. 7:375. doi: 10.1038/s41598-017-00 $342-1$

Hagemann, C., Fuchs, S., Monoranu, C. M., Herrmann, P., Smith, J., Hohmann, T., et al. (2013). Impact of MACC1on human malignant glioma progression and patients' unfavorable prognosis. Neuro. Oncol. 15, 1696-1709. doi: 10.1093/ neuonc/not136

Hegde, V. L., Nagarkatti, M., and Nagarkatti, P. S. (2010). Cannabinoid receptor activation leads to massive mobilization of myeloid-derived suppressor cells with potent immunosuppressive properties. Eur J Immunol. 40, 3358-3371. doi: 10.1002/eji.201040667.Cannabinoid

Herrera, M. I., Udovin, L. D., Toro-urrego, N., and Kusnier, C. F. (2018). Palmitoylethanolamide ameliorates hippocampal damage and behavioral dysfunction after perinatal asphyxia in the immature rat brain. Front Neurosci. 12:145. doi: 10.3389/fnins.2018.00145

Hezel, M., Ebrahimi, F., Koch, M., and Dehghani, F. (2012). Propidium iodide staining: a new application in fluorescence microscopy for analysis of cytoarchitecture in adult and developing rodent brain. Micron 43, 1031-1038. doi: 10.1016/j.micron.2012.04.006

Ho, W.-S., Barrett, D., and Randall, M. (2008). “Entourage " effects of N -palmitoylethanolamide and $\mathrm{N}$-oleoylethanolamide on vasorelaxation to anandamide occur through TRPV1 receptors. Br. J. Pharmocol. 155, 837-846. doi: 10.1038/bjp.2008.324

Hohmann, T., Feese, K., Greither, T., Ghadban, C., Jäger, V., Dehghani, F., et al. (2019). Synthetic cannabinoids influence the invasion of glioblastoma cell lines in a cell- and receptor-dependent manner. Cancers 11, 1-20. doi: 10.3390/ cancers 11020161

Hohmann, T., Grabiec, U., Ghadban, C., Feese, K., and Dehghani, F. (2017). The influence of biomechanical properties and cannabinoids on tumor invasion. Cell Adh. Migr. 11, 54-67. doi: 10.1080/19336918.2016.118 3867

Impellizzeri, D., Siracusa, R., Cordaro, M., Peritore, A. F., Gugliandolo, E., D'Amico, R., et al. (2019). N-Palmitoylethanolamine-oxazoline (PEA-OXA): a new therapeutic strategy to reduce neuroinflammation, oxidative stress associated to vascular dementia in an experimental model of repeated bilateral common carotid arteries occlusion. Neurobiol. Dis 125, 77-91. doi: 10.1016/j. nbd.2019.01.007

Járai, Z., Wagner, J. A., Varga, K., Lake, K. D., Compton, D. R., Martin, B. R., et al. (1999). Cannabinoid-induced mesenteric vasodilation through an endothelial site distinct from $\mathrm{CB} 1$ or $\mathrm{CB} 2$ receptors. Proc. Natl. Acad. Sci. U.S.A. 96, 14136-14141. doi: 10.1073/pnas.96.24. 14136
Jassam, Y. N., Izzy, S., Whalen, M., Mcgavern, D. B., and El Khoury, J. (2017). Review neuroimmunology of traumatic brain injury: time for a paradigm shift. Neuron 95, 1246-1265. doi: 10.1016/j.neuron.2017. 07.010

Jonsson, K.-O., Vandevoorde, S., Lambert, D. M., Tiger, G., and Fowler, C. J. (2001). Effects of homologues and analogues of palmitoylethanolamide upon the inactivation of the endocannabinoid anandamide. Br. J. Pharmocology 133, 1263-1275. doi: 10.1038/sj.bjp.070 4199

Kakizawa, H., Matsui, F., Tokita, Y., Hirano, K., Okumura, A., Kojima, S., et al. (2007). Neuroprotective effect of nipradilol, an NO donor, on hypoxic ischemic brain injury of neonatal rats. Early Hum. Dev. 83, 535-540. doi: 10.1016/j.earlhumdev.2006.10.003

Kallendrusch, S., Kremzow, S., Nowicki, M., Grabiec, U., Winkelmann, R., Benz, A., et al. (2013). The G protein-coupled receptor 55 Ligand L - a lysophosphatidylinositol exerts after excitotoxic lesion. Glia 61, 1822-1831. doi: 10.1002/glia.22560

Kettenmann, H., Hanisch, U.-K., Noda, M., and Verkhratsky, A. (2011). Physiology of microglia. Physiol. Rev. 91, 461-553. doi: 10.1152/physrev.00011. 2010

Koch, M., Kreutz, S., Boettger, C., Benz, A., Maronde, E., Ghadban, C., et al. (2011a). Palmitoylethanolamide protects dentate gyrus granule cells via peroxisome proliferator-activated receptor-alpha. Neurotox. Res. 19, 330-340. doi: 10.1007/s12640-010-9166-2

Koch, M., Kreutz, S., Böttger, C., Grabiec, U., Ghadban, C., Korf, H. W., et al. (2011b). The cannabinoid WIN 55,212-2-mediated protection of dentate gyrus granule cells is driven by $\mathrm{CB} 1$ receptors and modulated by TRPA1 and Ca v2.2 channels. Hippocampus 21, 554-564. doi: 10.1002/hipo. 20772

Kohl, A., Dehghani, F., Korf, H., and Hailer, N. P. (2003). The bisphosphonate clodronate depletes microglial cells in excitotoxically injured organotypic hippocampal slice cultures. Exp. Neurol. 181, 1-11. doi: 10.1016/S00144886(02)00049-3

Kömüves, L. G., Hanley, K., Lefebvre, A.-M., Man, M.-Q., Ng, D. C., Bikle, D. D., et al. (2000). Stimulation of PPAR a promotes epidermal keratinocyte differentiation In Vivo. J. Invest. Dermatol. 115, 353-360. doi: 10.1046/j.15231747.2000.00073.x

Kondo, S., Kondo, H., Nakane, S., Kodaka, T., Tokumura, A., Waku, K., et al. (1998). 2-Arachidonoylglycerol, an endogenous cannabinoid receptor agonist: identification as one of the major species of monoacylglycerols in various rat tissues, and evidence for its generation through Ca2+ + -dependent and -independent mechanisms. FEBS Lett. 429, 152-156. doi: 10.1016/s00145793(98)00581-x

Kozak, K. R., Gupta, R. A., Moody, J. S., Ji, C., Boeglin, W. E., Dubois, R. N., et al. (2002). 15-Lipoxygenase metabolism of 2Arachidonylglycerol. J. Biol. Chem. 277, 23278-23286. doi: 10.1074/jbc.M20108 4200

Kreutz, S., Koch, M., Böttger, C., Ghadban, C., Korf, H. W., and Dehghani, F. (2009). 2-Arachidonoylglycerol elicits neuroprotective effects on excitotoxically lesioned dentate gyrus granule cells via abnormal-cannabidiolsensitive receptors on microglial cells. Glia 57, 286-294. doi: 10.1002/glia. 20756

Kreutz, S., Koch, M., Ghadban, C., Korf, H., and Dehghani, F. (2007). Cannabinoids and neuronal damage: differential effects of THC, AEA and 2-AG on activated microglial cells and degenerating neurons in excitotoxically lesioned rat organotypic hippocampal slice cultures. Exp. Neurol. 203, 246-257. doi: 10. 1016/j.expneurol.2006.08.010

Kunz, A., Dirnagl, U., and Mergenthaler, P. (2010). Acute pathophysiological processes after ischaemic and traumatic brain injury. Best Pract. Res. Clin. Anaesthesiol. 24, 495-509. doi: 10.1016/j.bpa.2010. 10.001

Lau, A., and Tymianski, M. (2010). Glutamate receptors, neurotoxicity and neurodegeneration. Pflugers Arch. Eur. J. Physiol. 460, 525-542. doi: 10.1007/ s00424-010-0809-1

Lipina, C., and Hundal, H. S. (2017). The endocannabinoid system: "NO " longer anonymous in the control of nitrergic signalling? J. Mol. Cell Biol. 9, 91-103. doi: $10.1093 / \mathrm{jmcb} / \mathrm{mjx} 008$ 
Lourbopoulos, A., Grigoriadis, N., Lagoudaki, R., Touloumi, O., Polyzoidou, E., Mavromatis, I., et al. (2011). Administration of 2-arachidonoylglycerol ameliorates both acute and chronic experimental autoimmune encephalomyelitis. Brain Res. 1390, 126-141. doi: 10.1016/j.brainres.2011. 03.020

LoVerme, J., La Rana, G., Russo, R., Calignano, A., and Piomelli, D. (2005). The search for the palmitoylethanolamide receptor. Life Sci. 77, 1685-1698. doi: 10.1016/j.lfs.2005.05.012

Luongo, L., Palazzo, E., Tambaro, S., Giordano, C., Gatta, L., Scafuro, M. A., et al. (2010). 1-(2',4'-dichlorophenyl)-6-methyl-N-cyclohexylamine-1,4dihydroindeno[1,2-c] pyrazole-3-carboxamide, a novel CB2 agonist, alleviates neuropathic pain through functional microglial changes in mice. Neurobiol. Dis. 37, 177-185. doi: 10.1016/j.nbd.2009.09.021

Ma, L., Jia, J., Liu, X., Bai, F., Wang, Q., and Xiong, L. (2015). Biochemical and Biophysical Research Communications Activation of murine microglial N9 cells is attenuated through cannabinoid receptor CB2 signaling. Biochem. Biophys. Res. Commun. 458, 92-97. doi: 10.1016/j.bbrc.2015.01.073

Magid, L., Heymann, S., Elgali, M., Avram, L., Cohen, Y., Liraz-zaltsman, S., et al. (2019). The Role of CB 2 Receptor in the Recovery of Mice after Traumatic Brain Injury. J. Neurotrauma 36, 1836-1846. doi: 10.1089/neu.2018.6063

Meaney, D. F., Morrison, B., and Bass, C. D. (2014). The mechanics of traumatic brain Injury: a review of what we know and what we need to know for reducing its societal burden. J. Biomech. Eng. 136:021008. doi: 10.1115/1.4026364

Mechoulam, R., and Shohami, E. (2007). Endocannabinoids and traumatic brain injury. Mol. Neurobiol. 36, 68-74. doi: 10.1007/s12035-007-8008-6

Mounsey, R. B., Mustafa, S., Robinson, L., Ross, R. A., Riedel, G., Pertwee, R. G., et al. (2015). Increasing levels of the endocannabinoid 2-AG is neuroprotective in the Parkinson 's disease. Exp. Neurol. 273, 36-44. doi: 10.1016/j.expneurol. 2015.07.024

Muccioli, G. G., and Stella, N. (2009). Microglia produce and hydrolyze palmitoylethanolamide. Neuropharmacology 54, 16-22. doi: 10.1016/j. neuropharm.2007.05.015

Muccioli, G. G., Xu, C., Odah, E., Cudaback, E., Cisneros, J. A., Lambert, D. M., et al. (2007). Identification of a Novel Endocannabinoid-Hydrolyzing Enzyme Expressed by Microglial Cells. J. Neurosci. 27, 2883-2889. doi: 10.1523/ JNEUROSCI.4830-06.2007

Musella, A., Fresegna, D., Rizzo, F. R., Gentile, A., Bullitta, S., and De Vito, F. (2017). A novel crosstalk within the endocannabinoid system controls GABA transmission in the striatum. Sci. Rep. 7, 1-8. doi: 10.1038/s41598-017-07519-8

Nakamura, Y., Si, Q. S., and Kataoka, K. (1999). Lipopolysaccharide-induced microglial activation in culture: temporal profiles of morphological change and release of cytokines and nitric oxide. Neurosci. Res. 35, 95-100. doi: 10.1016/ s0168-0102(99)00071-1

Nimmerjahn, A., Kirchhoff, F., and Helmchen, F. (2005). Resting microglial cells are highly dynamic surveillants of brain parenchyma In Vivo. Science 308, 1314-1319.

Panikashvili, D., Simeonidou, C., Ben-shabat, S., Breuer, A., Mechoulam, R., and Shohami, E. (2001). An endogenous cannabinoid (2-AG) is neuroprotective after brain injury. Nature 413, 527-531. doi: 10.1038/35097089

Paterniti, I., Impellizzeri, D., Crupi, R., Morabito, R., Campolo, M., Esposito, E., et al. (2013). Molecular evidence for the involvement of PPAR- $\delta$ and PPAR- $\gamma$ in anti-inflammatory and neuroprotective activities of palmitoylethanolamide after spinal cord trauma. J. Neuroinflammation 10, 1-13. doi: 10.1186/17422094-10-20

Pertwee, R. G. (2014). Elevating endocannabinoid levels: pharmacological strategies and potential therapeutic applications. Proc. Nutr. Soc. 73, 96-105. doi: $10.1017 /$ S0029665113003649

Pertwee, R. G., Howlett, A. C., Abood, M. E., Alexander, S. P. H., Marzo, V., Di Elphick, M. R., et al. (2010). International union of basic and clinical pharmacology . LXXIX . cannabinoid receptors and their ligands: beyond $\mathrm{CB}$ 1 and CB 2. Pharmacol. Rev. 62, 588-631.

Petrosino, S., Moriello, A. S., Cerrato, S., Fusco, M., Puigdemont, A., De Petrocellis, L. X., et al. (2016). The anti-inflammatory mediator palmitoylethanolamide enhances the levels of 2-arachidonoyl-glycerol and potentiates its actions at TRPV1 cation channels. Br. J. Pharmocol. 173, 1154-1162. doi: 10.1111/bph. 13084

Portavella, M., Rodriguez-espinosa, N., Galeano, P., Blanco, E., and Romero, J. I. (2018). Oleoylethanolamide and Palmitoylethanolamide Protect Cultured
Cortical Neurons Against Hypoxia. Cannabis Cannabinoid Res. 3, 171-178. doi: $10.1089 /$ can.2018.0013

Ransohoff, R. M. (2016). A polarizing question: do M1 and M2 microglia exist? Nat. Neurosci. 19, 987-991. doi: 10.1038/nn.4338

Ross, R. A., Brockie, H. C., and Pertwee, R. G. (2000). Inhibition of nitric oxide production in RAW264.7 macrophages by cannabinoids and palmitoylethanolamide. Eur. J. Pharmacol. 401, 121-130. doi: 10.1016/s00142999(00)00437-4

Scotter, E. L., Abood, M. E., and Glass, M. (2010). The endocannabinoid system as a target for the treatment of neurodegenerative disease. Br. J. Pharmocology 160 , 480-498. doi: 10.1111/j.1476-5381.2010.00735.x

Siracusa, R., Impellizzeri, D., Cordaro, M., Crupi, R., and Cuzzocrea, S. (2017). Anti-inflammatory and neuroprotective effects of Co-UltraPEALut in a mouse model of vascular dementia. Front. Neurol. 8:233. doi: 10.3389/fneur.2017. 00233

Skaper, S. D., and Facci, L. (2014). Mast cells, glia and neuroinflammation: partners in crime? Immunology 141, 314-327. doi: 10.1111/imm.12170

Smart, D., Jonsson, K.-O., Vandevoorde, S., Lambert, D. M., and Fowler, C. J. (2002). ' Entourage' effects of N -acyl ethanolamines at human vanilloid receptors. Comparison of e $€$ ects upon anandamide-induced vanilloid receptor activation and upon anandamide metabolism. Br. J. Pharmocology 136, 452458. doi: $10.1038 /$ sj.bjp. 0704732

Smith, J. A., Das, A., Ray, S. K., and Banik, N. L. (2012). Role of pro-inflammatory cytokines released from microglia in neurodegenerative diseases. Brain Res. Bull. 87, 10-20. doi: 10.1016/j.brainresbull.2011.10.004

Stefano, G. B., Bilfinger, T. V., Rialas, C. M., and Dale, G. (2000). 2-arachidonylglycerol stimulates nitric oxide release from human immune and vascular tissues and invertebrate immunocytes by cannabinoid receptor 1. Pharmacol. Res. 42, 317-322. doi: 10.1006/phrs.2000.0702

Stella, N. (2009). Endocannabinoid signaling in microglial cells. Neuropharmacology 56, 244-253. doi: 10.1016/j.neuropharm.2008.07.037. Endocannabinoid

Umemoto, T., and Fujiki, Y. (2012). Ligand-dependent nucleo-cytoplasmic shuttling of peroxisome proliferator-activated receptors, PPAR a and PPAR c. Genes Cells 17, 576-596. doi: 10.1111/j.1365-2443.2012.01 607.x

Vincent, V. A. M., Tilders, F. J. H., and Van Dam, A.-M. (1998). Production, regulation and role of nitric oxide in glial cells. Mediators Inflamm. 7, 239-255. doi: $10.1080 / 09629359890929$

Vinet, J., van Weering, H. R., Heinrich, A., Kälin, R. E., Wegner, A., Brouwer, N., et al. (2012). Neuroprotective function for ramified microglia in hippocampal excitotoxicity. J. Neuroinflamm. 9:27. doi: 10.1186/1742-2094-9-27

Walter, L., Franklin, A., Witting, A., Wade, C., Xie, Y., Kunos, G., et al. (2003). Nonpsychotropic cannabinoid receptors regulate microglial cell migration. J. Neurosci. 23, 1398-1405. doi: 10.1002/glia.20813

Wang, F., Li, M., Li, X., Kinden, R., Zhou, H., Guo, F., et al. (2015). 2-AG protects primary astrocytes exposed to oxygen-glucose deprivation through a blockade of NDRG2 signaling and STAT3 phosphorylation. Exp. Neurol. 273, 1-25. doi: 10.1089/rej.2015.1703

Wang, S., Zhang, H., Geng, B., Xie, Q., Li, W., Deng, Y., et al. (2018). 2arachidonyl glycerol modulates astrocytic glutamine synthetase via p38 and ERK1 / 2 pathways. J. Neuroinflamm. 15, 1-10. doi: 10.1186/s12974-0181254-x

Warden, A., Truitt, J., Merriman, M., Ponomareva, O., Jameson, K., Ferguson, L. B., et al. (2016). Localization of PPAR isotypes in the adult mouse and human brain. Sci. Rep. 6, 1-15. doi: 10.1038/srep27618

Xu, J., Chavis, J. A., Racke, M. K., and Drew, P. D. (2006). Peroxisome proliferatoractivated receptor- a and retinoid X receptor agonists inhibit inflammatory responses of astrocytes. J. Neuroimmunol. 176, 95-105. doi: 10.1016/j.jneuroim. 2006.04.019

Xu, J., Storer, P. D., Chavis, J. A., Racke, M. K., Drew, P. D., and Rock, L. (2005). Agonists for the peroxisome proliferator- activated receptor- a and the retinoid $\mathrm{X}$ receptor inhibit inflammatory responses of microglia. J. Neurosci. Res. 411, 403-411. doi: 10.1002/jnr.20518

Yao, X., Liu, S., Ding, W., Yue, P., Jiang, Q., Zhao, M., et al. (2017). TLR4 signal ablation attenuated neurological de fi cits by regulating microglial M1 / M2 phenotype after traumatic brain injury in mice. J. Neuroimmunol. 310, 38-45. doi: 10.1016/j.jneuroim.2017.06.006 
Zhang, J., and Chen, C. (2008). Endocannabinoid 2-arachidonoylglycerol protects neurons by limiting COX-2 elevation. J. Biol. Chem. Biol. Chem. 283, 2260122611. doi: 10.1074/jbc.M800524200

Zhang, J., Hoffert, C., Vu, H. K., Groblewski, T., Ahmad, S., Donnell, D. O., et al. (2003). Induction of CB2 receptor expression in the rat spinal cord of neuropathic but not in ${ }^{-}$ammatory chronic pain models. Eur. J. Neurosci. 17, 2750-2754. doi: 10.1046/j.1460-9568.2003.02704.x

Zhou, T., Huang, Z., Sun, X., Zhu, X., Zhou, L., Li, M., et al. (2017). Microglia polarization with M1 / M2 phenotype changes in rd1 mouse model of retinal degeneration. Front. Neuroanat. 11:77. doi: 10.3389/fnana.2017. 00077
Conflict of Interest: The authors declare that the research was conducted in the absence of any commercial or financial relationships that could be construed as a potential conflict of interest.

Copyright (๑ 2019 Hohmann, Pelzer, Kleine, Hohmann, Ghadban and Dehghani. This is an open-access article distributed under the terms of the Creative Commons Attribution License (CC BY). The use, distribution or reproduction in other forums is permitted, provided the original author(s) and the copyright owner(s) are credited and that the original publication in this journal is cited, in accordance with accepted academic practice. No use, distribution or reproduction is permitted which does not comply with these terms. 